\title{
Quantification of aerosol chemical composition using continuous single particle measurements
}

\author{
C.-H. Jeong ${ }^{1}$, M. L. McGuire ${ }^{1}$, K. J. Godri ${ }^{2}$, J. G. Slowik ${ }^{1, *}$, P. J. G. Rehbein ${ }^{1}$, and G. J. Evans ${ }^{1}$ \\ ${ }^{1}$ Southern Ontario Centre for Atmospheric Aerosol Research, University of Toronto, 200 College Street, Toronto, Ontario, \\ M5S 3E5, Canada \\ ${ }^{2}$ Division of Environmental Health \& Risk Management, School of Geography, Earth \& Environmental Sciences, University \\ of Birmingham, Edgbaston, Birmingham, B15 2TT, UK \\ * now at: Paul Scherrer Institute, 5232 Villigen PSI, Switzerland
}

Received: 5 November 2010 - Published in Atmos. Chem. Phys. Discuss.: 17 January 2011

Revised: 7 July 2011 - Accepted: 8 July 2011 - Published: 20 July 2011

\begin{abstract}
Mass concentrations of sulphate, nitrate, ammonium, organic carbon (OC), elemental carbon (EC) were determined from real time single particle data in the size range 0.1-3.0 $\mu \mathrm{m}$ measured by an Aerosol Time-of-Flight Mass Spectrometer (ATOFMS) at urban and rural sites in Canada. To quantify chemical species within individual particles measured by an ATOFMS, ion peak intensity of $\mathrm{m} / \mathrm{z}-97$ for sulphate, -62 for nitrate, +18 for ammonium, +43 for OC, and +36 for EC were scaled using the number and size distribution data by an Aerodynamic Particle Sizer (APS) and a Fast Mobility Particle Sizer (FMPS). Hourly quantified chemical species from ATOFMS single-particle analysis were compared with collocated fine particulate matter (aerodynamic diameter $<2.5 \mu \mathrm{m}, \mathrm{PM}_{2.5}$ ) chemical composition measurements by an Aerosol Mass Spectrometer (AMS) at a rural site, a Gas-Particle Ion Chromatograph (GPIC) at an urban site, and a Sunset Lab field OCEC analyzer at both sites. The highest correlation was found for nitrate, with correlation coefficients (Pearson $r$ ) of 0.89 (ATOFMS vs. GPIC) and 0.85 (ATOFMS vs. AMS). ATOFMS mass calibration factors, determined for the urban site, were used to calculate mass concentrations of the major $\mathrm{PM}_{2.5}$ chemical components at the rural site near the US border in southern Ontario. Mass reconstruction using the ATOFMS mass calibration factors agreed very well with the $\mathrm{PM}_{2.5}$ mass concentrations measured by a Tapered Element Oscillating Microbalance (TEOM, $r=0.86$ ) at the urban site and a light scattering monitor (DustTrak, $r=0.87$ ) at the rural site. In the urban
\end{abstract}

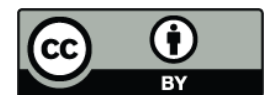

Correspondence to: G. J. Evans (greg.evans@utoronto.ca) area nitrate was the largest contributor to $\mathrm{PM}_{2.5}$ mass in the winter, while organics and sulphate contributed $\sim 64 \%$ of the summer $\mathrm{PM}_{2.5}$ in the rural area, suggesting a strong influence of regional/trans-boundary pollution. The mass concentrations of five major species in ten size-resolved particle-types and aerosol acidity of each particle-type were determined for the rural site. On a mass basis sulphate and OC rich particletypes (OC-S and OC-S-N) accounted for up to $59 \%$ of the particles characterized and aerosols were weakly acidic in the rural area. This is the first study to estimate hourly quantitative data of sulphate, nitrate, ammonium, OC and EC in ambient particles from scaled ATOFMS single particle analysis; these were closely comparable with collocated high time resolution data of sulphate, nitrate and ammonium detected by AMS and GPIC.

\section{Introduction}

Numerous epidemiological studies have revealed significant associations between adverse cardiorespiratory health and exposure to atmospheric particulate matter (PM) with an aerodynamic diameter less than $2.5 \mu \mathrm{m}\left(\mathrm{PM}_{2.5}\right)$ (e.g. Dockery et al., 1993; Burnett et al., 1995; Schwartz et al., 1996; Janssen et al., 2003). There have been deviations between the strength of the association identified by these studies, reflecting that the use of PM mass concentration is insensitive to heterogeneities in physical and chemical PM characteristics (Künzli et al., 2006). Toxicology studies have documented that specific PM components contribute to the observed toxicity: catalytic transition metals (Stohs and Bagchi 1995), surface adsorbed organics (polycyclic

Published by Copernicus Publications on behalf of the European Geosciences Union. 
aromatic hydrocarbons and quinones) (Squadrito et al., 2001) and endotoxins (Thorne, 2000) are able to elicit oxidative stress in the lung via their direct or indirect ability to generate reactive oxygen species (Pourazar et al., 2005).

A real-time, single particle instrument, such as an Aerosol Time-of-Flight Mass Spectrometer (ATOFMS), can provide size resolved chemical information on ambient PM in real time. To characterize individual ambient particles, ATOFMS instruments have been deployed in many sites in the US, the UK, Greece, Mexico, Ireland, Switzerland, China, the coast of India, and the coasts of Korea (e.g. Guazzotti et al., 2001; Middlebrook et al., 2003; Beddows et al., 2004; Dall'Osto and Harrison, 2006; Sullivan et al., 2007; Moffet et al., 2008, Zhang et al., 2009; Healy et al., 2010; Kamphus et al., 2010). Quantification of chemically resolved composition in ambient particles from single particle analyses is problematic mostly due to particle size, shape dependent transmission efficiency, chemical composition dependent ionization efficiency, and variability in ion intensity for identical particles (Allen et al., 2000; Kane and Johnston, 2000; Reilly et al., 2000; Wenzel and Prather, 2004). For quantitative analysis of mass spectra, peak areas of ions from a particle mass spectrometer were corrected using relative sensitivity factors for different ions determined from laboratory measurements with known chemical compositions (Hinz et al., 2005). However, the quantification method using relative sensitivity factors was limited by specific compounds in specific particle types (Hinz et al., 2005). Several studies have suggested procedures to scale ATOFMS measurements using collocated optical particle counters (Wenzel et al., 2003; Qin et al., 2006; Dall'Osto and Harrison, 2006; Ault et al., 2009). Scaled ATOFMS counts using APS data were found to compare well with $\mathrm{PM}_{2.5}$ mass concentrations (Ault et al., 2009). Size-resolved particle-types from single particle analysis data were also scaled with number concentrations measurements from a collocated Scanning Mobility Particle Sizer (SMPS) (Reinard et al., 2007; Pratt and Prather, 2009). The transmission bias was evaluated by comparing ATOFMS data with size segregated mass concentrations measured by a Micro-Orifice Uniform Deposit Impactor (MOUDI) (Allen et al., 2000; Bhave et al., 2002; Qin et al., 2006). Qin et al. (2006) and Dall'Osto et al. (2006) corrected for transmission losses by scaling with an Aerodynamic Particle Sizer (APS) and the scaled values agreed well with total $\mathrm{PM}_{2.5}$ mass concentrations and 24-h sampled chemical species collected by a MOUDI. Spencer and Prather (2006) compared unscaled organic carbon (OC) and elemental carbon (EC) fractions estimated from ATOFMS ion intensities with OC and EC concentrations determined using semi-continuous thermo-optical measurements. Ferge et al. (2006) reported that the ratio of EC to total carbon (TC, OC + EC) for laboratory generated particles derived from ATOFMS was comparable to the values determined by standard thermal techniques. Mass concentrations of particle classes derived from a clustering analysis of single particle data using another sin- gle particle mass spectrometer, a Real-time Single particle Mass Spectrometer (RSMS), were obtained by scaling size and chemical composition dependent detection efficiencies of RSMS (Tolocka et al., 2006; Bein et al., 2006; Reinard et al., 2007). Tolocka et al. (2006) found that mass concentrations of particle-types from RSMS single particle analysis did not always correlate well with continuous sulphate, nitrate, and carbon monitoring data. Specifically, during PM episodic days, the RSMS was found to be offset by a constant value as compared to the continuous monitors.

An ATOFMS was deployed in two winter/summer field campaigns conducted in downtown Toronto and Harrow, a metropolitan area and a rural area, respectively, in Southern Ontario, Canada. One of the objectives of these field campaigns was to compare the chemical components measured by the ATOFMS with collocated high time resolution measurements of sulphate, nitrate, and ammonium detected by an Aerodyne Aerosol Mass Spectrometer (AMS) and a Dionex Gas-Particle Ion Chromatography (GPIC). In the study, the quantitative measurements of particulate nitrate, sulphate, ammonium, OC, and EC ion markers in single particle mass spectra were obtained by scaling peak intensities (relative peak area and absolute peak area) of the marker ions measured by the ATOFMS. An enhanced procedure was developed to scale the ATOFMS transmission using both a TSI 3321 APS and a TSI 3091 Fast Mobility Particle Sizer (FMPS). The quantitative chemical information estimated using ATOFMS ion intensity data was compared to collocated high-time resolution chemical species concentrations measured by an Aerodyne AMS, a Dionex GPIC, and a Sunset Lab field thermal-optical OCEC (Sunset OCEC) analyzer in both the urban and rural locations.

Mass concentrations of major chemical species were estimated using the ATOFMS, based on linear correlation analysis between the scaled ATOFMS and measurements by the GPIC as well as the Sunset OCEC analyzer. Total $\mathrm{PM}_{2.5}$ mass concentrations were reconstructed from the ATOFMS chemical species at the two sites and evaluated by comparison with measured $\mathrm{PM}_{2.5}$ mass concentrations.

\section{Experimental methods}

\subsection{Sampling sites and measurements}

An ATOFMS (TSI 3800-100) was deployed in downtown Toronto, Ontario, Canada from 20 January 2007 to 5 February 2007 as a part of the Seasonal Particulate Observation in Regional Toronto (SPORT) campaign (Fig. 1). The Toronto site $\left(43^{\circ} 39^{\prime} 32.40^{\prime \prime} \mathrm{N}, 79^{\circ} 23^{\prime} 43.33^{\prime \prime} \mathrm{W}\right)$, a roadside building at the Southern Ontario Centre for Atmospheric Aerosol Research (SOCAAR) of the University of Toronto, is located at the intersection of high traffic local streets ( 233000 vehicles/weekday). Busy expressways were situated to the east $(\sim 3 \mathrm{~km})$ and south $(\sim 2 \mathrm{~km})$ of the monitoring site. The 


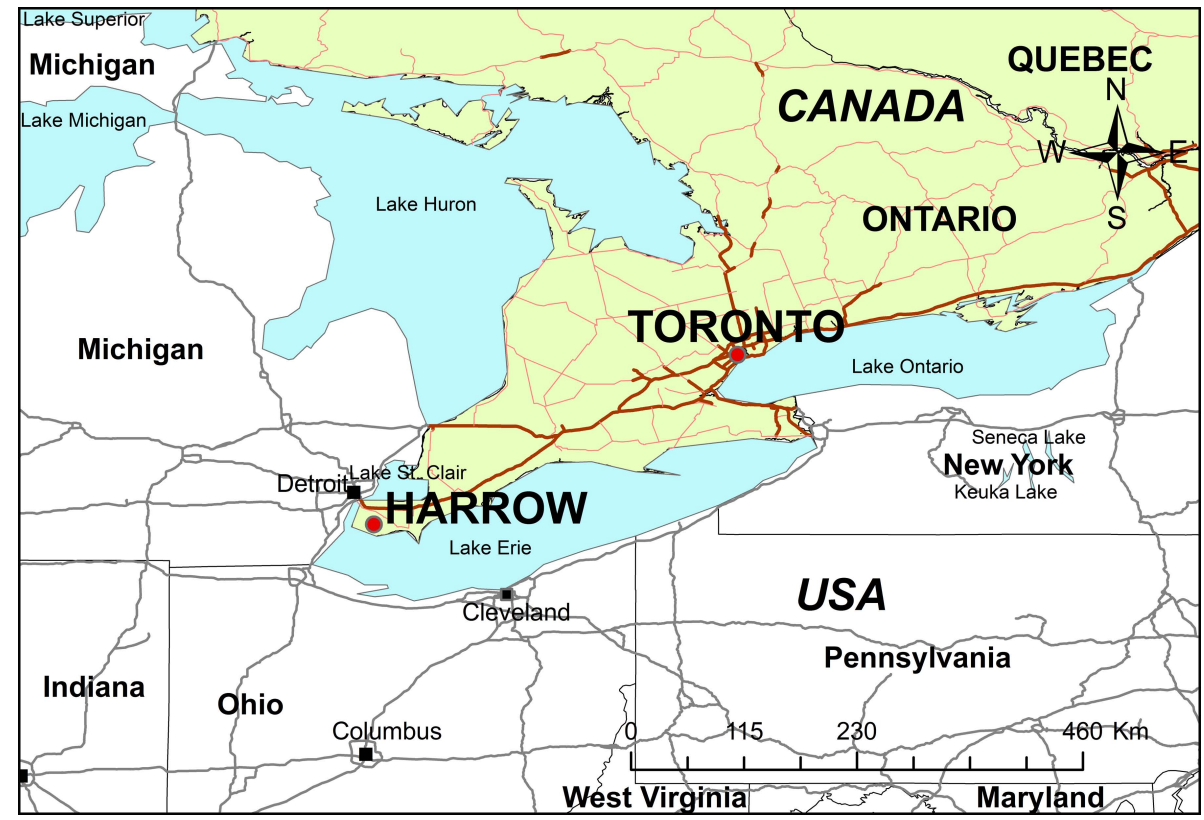

Fig. 1. Locations of monitoring sites during the SPORT (Toronto) and BAQS-Met (Harrow) campaigns.

main sampling inlet of the SOCAAR laboratory was approximately $15 \mathrm{~m}$ from the road and $6 \mathrm{~m}$ above ground level. The diameter of the insulated sampling inlet was $\sim 10 \mathrm{~cm}$ and the length was $\sim 8 \mathrm{~m}$. The sampling flow rate was $\sim 1501 \mathrm{~min}^{-1}$. During the SPORT campaign, the ATOFMS was deployed with other collocated chemical speciation instruments; a GPIC and a Sunset OCEC analyzer.

The Border Air Quality and Meteorology Study (BAQSMet 2007) was a summer intensive field study conducted in several locations across southern Ontario to investigate the influence of local and trans-boundary transported pollutants on local air quality. As part of the BAQS-Met 2007 an ATOFMS was deployed in a rural area in Harrow, Ontario, Canada $\left(42^{\circ} 1^{\prime} 58.95^{\prime \prime} \mathrm{N}, 82^{\circ} 53^{\prime} 35.61^{\prime \prime} \mathrm{W}\right) \sim 340 \mathrm{~km}$ southwest of the Toronto site for the period 19 June to 11 July 2007 (Fig. 1). The Harrow site located near Lake Erie was influenced by local industrial sites including the Detroit-Windsor industrial area and long-range transported emissions from industrial areas in the midwestern US. Measurements were performed in SOCAAR's mobile lab (MAPLE) using a stainless steel sampling tubing ( $2.5 \mathrm{~cm}$ in diameter, $5 \mathrm{~m}$ long) at a flow rate of $\sim 301 \mathrm{~min}^{-1}$. During the BAQS-Met 2007 campaign, a Time-of-Flight Aerodyne AMS was also simultaneously deployed. Comparisons were made between the ATOFMS quantitative measurements and corresponding chemical speciation data provided by the AMS and Sunset OCEC analyzer.

Basic instrumental descriptions of a TSI 3800 ATOFMS are presented in detail elsewhere (e.g. Gard et al., 1997). In brief, ambient particles $\left(0.11 \mathrm{~min}^{-1}\right)$ are drawn through an Aerodynamic Focusing Lens (AFL, TSI AFL-100) to the
ATOFMS sizing region. In this particle sampling region the aerosols are accelerated to their terminal velocities depending on their aerodynamic diameters, which are then determined by measuring the transit time between two $50 \mathrm{~mW}$ Nd:YAG lasers $(532 \mathrm{~nm})$ in the sizing region. Once the particles enter the mass spectrometer region, a UV laser (Nd:YAG $266 \mathrm{~nm}, \sim 10^{8} \mathrm{~W} \mathrm{~cm}^{-2}$ ) desorbs and ionizes the particles to produce positive and negative ions. These ions are accelerated and dual-polarity mass spectra for individual particles are measured. Polystyrene latex sphere (PSL, 0.2-2.1 $\mu \mathrm{m}$ ) and TSI metal solutions were used for particle size and mass spectra calibration.

One hour averaged concentrations of sulphate, nitrate, ammonium, and organics measured by the AMS were compared to the corresponding PM speciation concentrations measured by the ATOFMS. The AMS collection efficiencies (CE) were determined from the AMS light scattering module at Harrow (Quinn et al., 2006). The AMS data were corrected for the CE, varying between 0.5 and 1 . The transmission particle size range of the AMS was less than $1 \mu \mathrm{m}$, representing $\mathrm{PM}_{1}$ chemical component measurements, with nearly $100 \%$ transmission efficiency for particles between $0.07-0.50 \mu \mathrm{m}$ (Jayne et al., 2000). A detailed description of an AMS is provided elsewhere (Jayne et al., 2000; Jimenez et al., 2003).

The GPIC measured water soluble particulate components $\left(\mathrm{SO}_{4}^{2-}, \mathrm{NO}_{3}^{-}, \mathrm{NO}_{2}^{-}, \mathrm{NH}_{4}, \mathrm{Cl}^{-}\right)$and gaseous precursors $\left(\mathrm{SO}_{2}, \mathrm{HNO}_{3}, \mathrm{HNO}_{2}, \mathrm{NH}_{3}, \mathrm{HCl}\right)$ every $15 \mathrm{~min}$, while the semi-continuous Sunset Lab field OCEC analyzer determined $\mathrm{PM}_{2.5} \mathrm{OC}$ and EC using the thermal-optical transmission (TOT) method with 2-h time resolution. Detailed descriptions of the GPIC and Sunset OCEC analyzer can be 
found elsewhere (Godri et al., 2009; Jeong et al., 2004). Hourly $\mathrm{PM}_{2.5}$ data measured by a Tapered Element Oscillating Microbalance (TEOM) were obtained from the Toronto downtown monitoring site operated by the Ontario Ministry of the Environment, approximately $900 \mathrm{~m}$ northeast of the SOCAAR site. Since the heated inlet of the TEOM was operated at $40^{\circ} \mathrm{C}$, a negative artifact due to the loss of ammonium nitrate and semivolatile organics was expected in the TEOM PM $\mathrm{P}_{2.5}$ mass data. During the BAQS-Met campaign, continuous $\mathrm{PM}_{2.5}$ mass concentrations were measured by a TSI 8520 DustTrak monitor and a Met One instrument 1020 Beta Attenuation Monitor (BAM) deployed by Environment Canada.

\subsection{Data analysis}

During the SPORT and the BAQS-Met campaigns, 1806910 and 183410 particles were sized, respectively, and both size and positive/negative mass spectra data (hit particles) were collected for 588570 and 66920 ambient particles by the ATOFMS. The ion intensity for each mass to charge ratio $(\mathrm{m} / \mathrm{z})$ within a particle mass spectrum was expressed as arbitrary units (AU), a measure of the number of ions of this $\mathrm{m} / \mathrm{z}$ detected. All individual particle mass spectra were converted into a peak list using TSI MS-Analyze software with the following detection limit criteria: a peak had to contain at least $20 \mathrm{AU}$ above the baseline, have at least 20 squared $\mathrm{AU}$ of area, and represent more than $0.1 \%$ of the total AU detected for the particle.

Mass to charge ratio values within the positive and negative spectra were selected to estimate quantitative concentrations of the major chemical components in single particle mass spectra. The best $\mathrm{m} / \mathrm{z}$ candidates for the major components were determined by comparing hourly particle counts from $\mathrm{m} / \mathrm{z}-100$ to +100 with relevant chemical concentrations obtained by the AMS and Sunset OCEC analyzer. A short list of ATOFMS $m / z$ values were initially selected as candidate markers based on their strong correlation with chemical composition measured by the collocated instruments. The final ATOFMS $m / z$ markers selected for sulphate, nitrate, ammonium, OC, and EC were $m / z-97\left[\mathrm{HSO}_{4}^{-}\right],-62$ $\left[\mathrm{NO}_{3}^{-}\right],+18\left[\mathrm{NH}_{3}^{+}\right],+43\left[\mathrm{C}_{3} \mathrm{H}_{7}^{+} / \mathrm{C}_{2} \mathrm{H}_{3} \mathrm{O}^{+} / \mathrm{CHNO}^{+}\right]$, and $+36\left[\mathrm{C}_{3}^{+}\right]$; the corresponding mass to charge peaks were integrated over \pm 0.4 Daltons. It should be noted that the use of multiple ions for a compound was also explored, (e.g. using the sum of $m / z-97\left[\mathrm{HSO}_{4}^{-}\right]$and $-80\left[\mathrm{SO}_{3}^{-}\right]$for sulphate). However, there was no improvement in the correlation between the ATOFMS ions peaks and the other collocated measurements. Hence a single $m / z$ was selected as the marker for each aerosol component.

The particle detection efficiency of the ATOFMS depends on the ability of the instrument to transport particles though the sizing region as well as to detect the particles with two sizing lasers (the transmission efficiency) and the capacity of the particle to then absorb ablation laser photons in order to produce a measurable mass spectrum (the hit efficiency). Thus the detection efficiency depends on particle size, shape and composition (Allen et al., 2000; Kane and Johnston, 2000). The lower transmission efficiencies of smaller sizes in the ATOFMS create a bias towards particles of a given size range. In this work the number concentrations of particles hit by the ATOFMS for twelve size bins between $0.1 \mu \mathrm{m}$ and $3.0 \mu \mathrm{m}$ were scaled by the particle number concentrations simultaneously measured by an APS and an FMPS to correct for the detection efficiency. The APS measured the size distribution of particles from $0.5 \mu \mathrm{m}$ to $20 \mu \mathrm{m}$ in aerodynamic diameter with $1 \mathrm{~min}$ resolution. The APS also detected particles smaller than $0.5 \mu \mathrm{m}$ using a light scattering mode. However, these light scattering data were not used due to the associated high uncertainty (Peters and Leith, 2003). Instead, particle number size distributions in the $0.1 \mu \mathrm{m}$ to $0.5 \mu \mathrm{m}$ range measured by the FMPS were selected for the ATOFMS count correction. The FMPS provided particle size distributions from $0.06 \mu \mathrm{m}$ to $0.56 \mu \mathrm{m}$ (electronic mobility diameter) with 1-s time resolution. The FMPS has been described in detail elsewhere (Jeong and Evans, 2009). We should note that calibrations with standard PSL particles of known size indicated that the FMPS underestimates the size of particles larger than $0.1 \mu \mathrm{m}$. Thus corrections factors were developed and applied based on these PSL particles. Application of this size correction was validated by comparing the size distributions for ambient particles measured by the FMPS and a SMPS (TSI 3936).

Since there is a difference between aerodynamic and the electrical mobility diameter determined by the FMPS, particle diameters obtained by the FMPS were converted to aerodynamic diameter to allow a proper comparison. The conversion given by Sioutas et al. (1999) and Hinds (1982) was used:

$d_{\mathrm{a}}=d_{\mathrm{m}} \sqrt{\frac{C_{\mathrm{c}, d_{\mathrm{m}}} \cdot \rho_{\mathrm{eff}}}{C_{\mathrm{c}, d_{\mathrm{a}}} \cdot \chi \cdot \rho_{0}}}$

where $\rho_{0}$ is the standard density $\left(1 \mathrm{~g} \mathrm{~cm}^{-3}\right), \rho_{\text {eff }}$ is the effective density, $d_{\mathrm{a}}$ is the aerodynamic diameter, $d_{\mathrm{m}}$ is the electrical mobility equivalent diameter, $C_{\mathrm{c}, d_{\mathrm{m}}}$ is the Cunningham slip correction factor for the mobility equivalent diameter, $C_{\mathrm{c}, d_{\mathrm{a}}}$ is the Cunningham slip correction factor for the aerodynamic diameter, and $\chi$ is the dynamic shape factor. The effective density depends on both material density and shape of the particle. In this study, $\chi$ and $\rho_{\text {eff }}$ were assumed to be 1 and $1.6 \mathrm{~g} \mathrm{~cm}^{-3}$, respectively. The effective density of $1.6 \mathrm{~g} \mathrm{~cm}^{-3}$ is comparable with the results from previous aerosol density studies (Hand and Kreidenweis, 2002; Khlystov et al., 2004; Pitz et al., 2008). These values were used in Eq. (1) to convert the FMPS mobility diameters in the size range of $0.09 \mu \mathrm{m}$ to $0.32 \mu \mathrm{m}$, to aerodynamic diameters ranging from $0.11 \mu \mathrm{m}$ to $0.50 \mu \mathrm{m}$. After transforming the FMPS scale from the mobility to the aerodynamic diameters, the APS and FMPS size distribution data were merged 
together in Fig. 2. Data for similar particle diameter at $\sim 0.5 \mu \mathrm{m}$ were in reasonable agreement in general. However, in the overlapping diameter range $(0.3 \mu \mathrm{m}-0.5 \mu \mathrm{m})$ the APS concentration was lower than the FMPS data by a factor of $\sim 2$ at both sites. This discrepancy might be due to the poorer counting efficiency of the TSI 3321 APS for the smallest particle size $(<0.5 \mu \mathrm{m})$ determined by only light scattering intensity information (Armendariz and Leith, 2002; Peters and Leith, 2003).

On average, the total number concentrations of particles in the size range of $0.01 \mu \mathrm{m}-2.50 \mu \mathrm{m}$ were $32600 \pm 800 \mathrm{~cm}^{-3}$ (mean \pm standard error) and $16000 \pm 600 \mathrm{~cm}^{-3}$ for the winter time in Toronto and for the summer time in Harrow, respectively. This difference was evident for particles smaller than $0.1 \mu \mathrm{m}$ and mostly due to the seasonal difference between the two sampling campaigns. The particle number concentrations in Toronto were $\sim 34 \%$ lower than those in Harrow during the summer (Jeong et al., 2010). For particles in the $0.1 \mu \mathrm{m}-0.5 \mu \mathrm{m}$ range the number concentration in Harrow was higher than the average in Toronto by a factor of 1.2, whereas the number concentration of the largest mode particles $(0.8 \mu \mathrm{m}-2.5 \mu \mathrm{m})$ was higher in Toronto than the average in Harrow by a factor of two. In order to estimate size-specific scaling factors for the ATOFMS measurements, the number concentrations were converted into volume concentrations. A descriptive summary of particle volume concentrations measured by the FMPS and APS in Toronto and Harrow, respectively, is shown in Table 1. As expected, the average volume concentrations of particles in the size range of $0.1 \mu \mathrm{m}-0.5 \mu \mathrm{m}$ detected by the FMPS were distinctly higher than the average volume concentrations $(0.3 \mu \mathrm{m}-0.5 \mu \mathrm{m})$ measured by the APS.

A scaling factor $(S)$ was defined as follows to correct for the ATOFMS' detection efficiency:

For $d_{\mathrm{a}}>0.52 \mu \mathrm{m}, S_{d_{\mathrm{a}, j}}=\frac{V_{j(\mathrm{APS})}}{V_{j(\mathrm{ATOFMS})}}$

For $d_{\mathrm{a}}<0.52 \mu \mathrm{m}, S_{d_{\mathrm{a}}<0.52 \mu \mathrm{m}}=\frac{V_{0.1-0.5 \mu \mathrm{m}(\mathrm{FMPS})}}{V_{d_{\mathrm{a}}<0.52 \mu \mathrm{m}(\text { ATOFMS })}}$

where $V_{j \text { (APS) }}$ and $V_{j \text { (ATOFMS) }}$ are the hourly total particle volume concentrations measured by the APS and ATOFMS measurements in the size bin $(j)$, respectively; $V_{0.1-0.5 \mu \mathrm{m} \text { (FMPS) }}$ is the hourly total volume concentration of particles in the range from $0.1 \mu \mathrm{m}$ to $0.5 \mu \mathrm{m}$ (aerodynamic diameter) measured by the FMPS; and $V_{d_{\mathrm{a}}<0.52 \mu \mathrm{m} \text { (ATOFMS) }}$ is the hourly total particle $\left(d_{\mathrm{a}}<0.52 \mu \mathrm{m}\right)$ volume concentration obtained by the ATOFMS. To calculate the total volume concentrations of particles $\left(d_{\mathrm{a}}<0.52 \mu \mathrm{m}\right)$ measured by the ATOFMS, an average diameter of $0.3 \mu \mathrm{m}$ was assumed. Even though number concentrations in the smaller size range were available for both the FMPS and the ATOFMS, integrated values were used for the quantification approach due to the poor detection efficiencies of the two instruments for

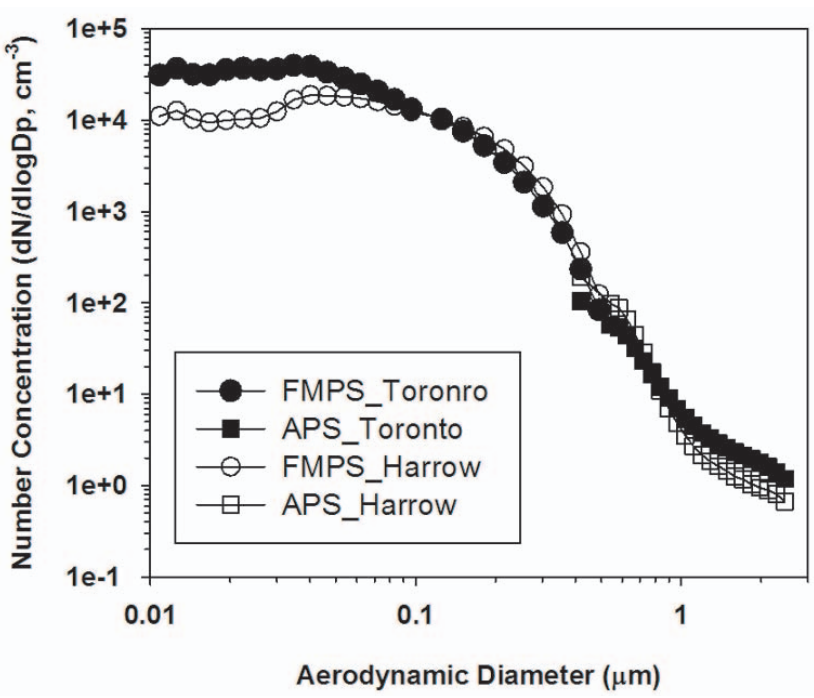

Fig. 2. Average size distributions of particles measured by the FMPS $(0.01 \mu \mathrm{m}-0.50 \mu \mathrm{m})$ and the APS $(0.30 \mu \mathrm{m}-2.50 \mu \mathrm{m})$ in Toronto and Harrow.

this range. The midpoints of 11 size bins for the scaling factor with the APS were $0.56,0.65,0.75,0.87,1.00,1.15,1.33$, $1.54,1.78,2.05$, and $2.37 \mu \mathrm{m}$ in this study.

We hypothesized that scaled ion intensities are linearly correlated with the volume concentrations of corresponding chemical components, and hence, relative peak areas (RPA) would be representative of the relative proportion of these chemical components in a single particle. Relative peak area was defined as the numbers of ions collected for a specific $\mathrm{m} / \mathrm{z}$ divided by the total number of ions produced from the ionization of the particle. This was calculated as the peak area (PA) of the specific ion intensity divided by the total peak area of the positive or negative mass spectrum. Hourly fractional volumes $\left(v_{i, k}, \mu \mathrm{m}^{3}\right)$ of individual particles $(i)$ for each ion marker $(k)$ were estimated from:

$v_{i, k}=\frac{\mathrm{RPA}_{i, k}}{2} \cdot \sum_{i} \frac{\pi}{6} d_{\mathrm{a} i, k}^{3}$

where $d_{\mathrm{a} i}$ is the measured diameter $(\mu \mathrm{m})$ of individual particle $(i)$ for ion marker $(k)$ and $\mathrm{RPA}_{i, k}$ is the ATOFMS relative peak area of $m / z$ 's corresponding to chemical species, i.e. sulphate, nitrate, ammonium, OC, and EC. The composition indicated by the RPA was scaled based on the volume of the particle. Note that this approach may have potential biases when the aerosol is heterogeneous and/or only partially ablated by the laser. A further bias can occur with the assumption that the particles are composed of only sulphate, nitrate, ammonium, OC, and EC. However, in terms of mass fractions of $\mathrm{PM}_{2.5}$ these five species are predominant chemical compositions. In five Canadian cities these five chemical species accounted for $66-85 \%$ of total $\mathrm{PM}_{2.5}$ mass concentrations determined by a TEOM, whereas most of metal 
Table 1. Descriptive statistics for hourly averaged particle volumetric concentrations $\left(\mu \mathrm{m}^{3} \mathrm{~cm}^{-3}\right)$ measured by the FMPS and APS during the SPORT in Toronto and the BAQS-Met in Harrow.

\begin{tabular}{lllcccccccc}
\hline & & $d_{\mathrm{a}}{ }^{\mathrm{a}}(\mu \mathrm{m})$ & Mean & Median & StDev $^{\mathrm{b}}$ & $\operatorname{Min}^{\mathrm{c}}$ & $\operatorname{Max}^{\mathrm{d}}$ & Lower Quartile $^{\text {Upper Quartile }} n^{\mathrm{e}}$ \\
\hline \multirow{2}{*}{ Toronto } & FMPS & $0.1-0.5$ & 8.23 & 6.60 & 4.95 & 1.84 & 29.0 & 4.40 & 11.1 & 375 \\
& APS & $0.3-0.5$ & 0.38 & 0.27 & 0.30 & 0.08 & 1.46 & 0.18 & 0.45 & 375 \\
& APS & $0.5-2.5$ & 3.49 & 3.03 & 2.63 & 0.58 & 22.0 & 2.12 & 4.09 & 375 \\
\hline \multirow{5}{*}{ Harrow } & FMPS & $0.1-0.5$ & 10.5 & 8.37 & 8.41 & 0.18 & 34.1 & 3.12 & 15.8 & 520 \\
& APS & $0.3-0.5$ & 0.68 & 0.39 & 0.72 & 0.01 & 3.62 & 0.14 & 1.02 & 520 \\
& APS & $0.5-2.5$ & 2.88 & 1.92 & 2.75 & 0.21 & 15.5 & 1.06 & 3.55 & 520 \\
\hline
\end{tabular}

${ }^{\mathrm{a}}$ Aerodynamic diameter; ${ }^{\mathrm{b}}$ standard deviation; ${ }^{\mathrm{c}}$ minimum; ${ }^{\mathrm{d}}$ maximum; ${ }^{\mathrm{e}}$ number of samples.

elements contributed only 4-7\% of the fine mass concentrations (Jeong et al., 2011).

Hourly scaled ATOFMS volume intensities $\left(V_{\mathrm{S}}, \mu \mathrm{m}^{3}\right)$ of chemical species were estimated using hourly size specific scaling factors for the corresponding species as follows:

$V_{\mathrm{S}}=v_{i, k} \cdot S_{d_{a i, k}}$

where $S_{d_{a}, k}$ is the size-resolved hourly scaling factor corresponding to chemical species $(k)$. Gross et al. (2000) reported that variations in relative peak areas of the ATOFMS ion intensity were smaller than absolute peak area variations for particles of identical composition. However, RPA values of positive and negative ions may also be affected by inherent variances of particle compositions due to matrix effects within particles and chemical specific ionization efficiencies (Reilly et al., 2000; Reinard and Johnston, 2008). The ionization efficiencies of alkali metals such as sodium and potassium are higher than any other measureable species because of their low ionization energies. The presence of these species may result in different ion formation processes than if they were absent, and as a result they may introduce systematic biases in measuring relative ion intensities (Reinard and Johnston, 2008).

Instead of using RPA, the hourly ATOFMS peak area (PA), as given in Eq. (6), was used to quantify chemical components.

$\mathrm{PA}_{\mathrm{s}}=\sum_{i} \mathrm{PA}_{i, k} \cdot S_{d_{\mathrm{a} i, k}}$

The scaled ATOFMS peak area was also compared with high time resolution PM speciation data. Also implicit to this method was the assumption that particles were fully ablated and thus the ion intensity for a given $\mathrm{m} / \mathrm{z}$ was proportional to the total amount of the corresponding component within the particle.

\subsection{Clustering analysis}

In order to group the mass spectra obtained by the ATOFMS into a small number of classes, logarithmic scale ATOFMS data were imported in a MATLAB-based software toolkit known as YAADA (www.yaada.org). Once imported, a clustering method based on the Adaptive Resonance Theory Artificial Neural Network (ART-2a) algorithm (Song et al., 1999; Phares et al., 2001) was applied with a vigilance factor of 0.3 and a learning rate of 0.05 . More details on the clustering analysis in this study are presented by McGuire et al. (2011). The 33 particle clusters obtained by running ART2a were manually re-grouped into 10 general particle-types based on their similarities in mass spectra, size distributions, and temporal trends. The manually re-grouped particle-types accounted for $99 \%$ of the total hit particles. In this study, hourly size-specific scaling factors were applied to individual particles to estimate the average mass composition of each particle-type in terms of the major chemical components in Harrow.

\section{Results and discussion}

\subsection{Detection efficiency of the ATOFMS}

The scaling factor as a function of particle size was estimated during the SPORT campaign in downtown Toronto and the BAQS-Met study at a rural site (Fig. S1 in Supplement). This scaling factor represents the inverse of the detection efficiency and accounts for losses due to transmission and ionization or chemical detection. The largest scaling factor ( $\sim 5.9 \times 10^{3}$ for Toronto, $\sim 1.5 \times 10^{5}$ for Harrow) was found for the smallest particle size bins $(<0.5 \mu \mathrm{m})$, corresponding to the lowest detection efficiency for particles smaller than $0.5 \mu \mathrm{m}$. The detection efficiency in Toronto, on average, was higher than in Harrow by approximately an order of magnitude for particles between $0.1 \mu \mathrm{m}$ and $2.5 \mu \mathrm{m}$. The difference in the efficiency was attributed in part to degraded performance of the sizing lasers and the photomultiplier of the 
ATOFMS at Harrow. The transmission, and hence detection, efficiency improved dramatically when these were later replaced after the Harrow campaign.

With respect to the field measurements, the chemical biases of ATOFMS data were indirectly examined by comparing the hit efficiency in a given size bin. The hit efficiency is defined as the number of particles for which both size and mass spectral data are obtained divided by the number of particles sized. Figure S2 presents the average hit efficiency as a function of particle size during the two field campaigns. On average, the hit efficiency was $29 \pm 14 \%$ in Toronto. During the BAQS-Met study in Harrow, the average hit efficiency for total particles was $27 \pm 20 \%$. Note that the ATOFMS laser pulse energy was kept at $\sim 1 \mathrm{~mJ} /$ pulse during the two campaigns. Overall, the highest hit efficiency was observed for the smaller ambient particles $(<0.5 \mu \mathrm{m})$ with an average efficiency of $38 \pm 11 \%$ in Toronto and $57 \pm 14 \%$ in Harrow.

Figure 3 presents the hit efficiency of particles smaller than $0.52 \mu \mathrm{m}$ at the two sites. In Toronto the hit efficiency on 23 January was very low, dropping sharply from approximately $55 \%$ to $13 \%$ as the concentrations of sulphate, nitrate and ammonium increased. In addition, there were strong negative correlations between continuous measurements of sulphate, nitrate, and ammonium determined by the GPIC and the hit efficiency in Toronto. A decrease in the hit efficiency during PM episodic days was also observed on 1-2 February at the Toronto site and on 25-26 June at the Harrow site (Fig. 3b). No correlation between relative humidity and the hit efficiency was observed, while ambient temperature was negatively correlated with the hit efficiency. It is likely that the increase of photochemical formation of secondary aerosol during the period of high temperature resulted in the deceased hit efficiency during these episodes; it is postulated that this reduced hit efficiency was due to coating of the particles with high albedo compounds such as ammonium sulphate and ammonium nitrate. In order to examine the effect of particle mixing state on the ATOFMS hit efficiency, the correlation between the hit efficiency and the ratio of EC to the sum of sulphate, nitrate, ammonium, and OC was analyzed. Pearson correlation coefficients $(r)$ were 0.50 $(p<0.05)$ at Toronto and $0.32(p<0.05)$ at Harrow. These positive correlations support the observation that reduced hit efficiency is associated with lower EC fractions (and thus higher fractions of coating constituents), indicating the influence of particle aging processes on the ATOFMS sensitivity. This finding is consistent with a previous ATOFMS scaling work, where particles composed of a significant amount of ammonium sulphate were postulated to be present during periods of low hit efficiency in the size range of $0.35-0.54 \mu \mathrm{m}$ (Wenzel et al., 2003).

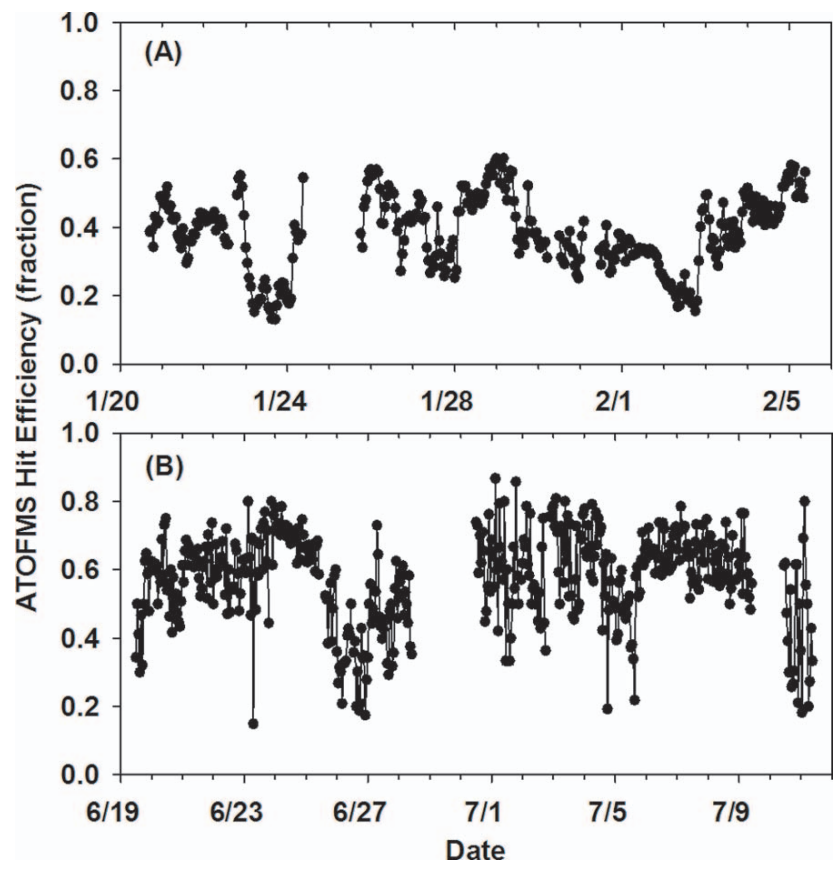

Fig. 3. ATOFMS hit efficiency for particle smaller than $0.52 \mu \mathrm{m}$ in Toronto (A) and Harrow (B).

\subsection{Comparison between scaled ATOFMS and collocated measurements}

Comparison analyses between scaled total particle volume obtained by the ATOFMS and collocated semi-continuous measurements of chemical composition in Toronto and Harrow are shown in Fig. 4 and Fig. 5. Table 2 provides a summary of the comparison between the quantitative data obtained using RPA and PA with the ATOFMS ion species peaks and the chemical species concentrations measured at the two sites. Unscaled total particle volume concentrations without inclusion of RPA or PA were also compared, as presented in Table 2.

In Toronto, fifteen minute average concentrations of nitrate, sulphate, and ammonium were measured by the GPIC, while two-hour-averaged OC and EC concentrations were obtained by the Sunset OCEC analyzer. During the SPORT campaign in Toronto, the highest correlation between the ATOFMS and the GPIC was observed for nitrate followed by ammonia and sulphate, as shown in Table 2. Note that scaling based on transmission efficiency improved the correlation; correlation coefficients (Pearson $r$ ) between the hourly-averaged ATOFMS relative peak areas scaled by both the APS and FMPS for sulphate, nitrate, and ammonium and hourly corresponding concentrations from the GPIC in Toronto were $0.79,0.89$, and 0.85 , respectively. Scaling ATOFMS using the APS alone, rather than the APS and FMPS together, lowered the Pearson correlation coefficients for nitrate $(r=0.70, p<0.05)$, while there was little change 
Table 2. Pearson correlation coefficients $(r)$ between unscaled/scaled ATOFMS ion intensities and the hourly Sunset OCEC, GPIC (Toronto), and AMS (Harrow) measurements.

\begin{tabular}{|c|c|c|c|c|c|c|c|c|}
\hline & & \multicolumn{3}{|c|}{$\begin{array}{l}\text { Unscaled } \\
\text { ATOFMS }^{\mathrm{a}}\end{array}$} & \multicolumn{2}{|c|}{$\begin{array}{c}\text { Scaled } \\
\text { ATOFMS }_{\mathrm{A}} \mathrm{c}\end{array}$} & \multicolumn{2}{|c|}{$\begin{array}{c}\text { Scaled } \\
\text { ATOFMS }_{\mathrm{AF}}{ }^{\mathrm{d}}\end{array}$} \\
\hline & & Volume $^{\mathrm{b}}$ & RPA & $\mathrm{PA}$ & RPA & PA & RPA & PA \\
\hline \multirow{5}{*}{ Toronto } & Sulphate $\left(n^{\mathrm{e}}=306\right)$ & 0.12 & 0.21 & 0.33 & 0.80 & 0.78 & 0.79 & 0.60 \\
\hline & Nitrate $(n=304)$ & 0.11 & 0.43 & 0.47 & 0.70 & 0.73 & 0.89 & 0.84 \\
\hline & Ammonium $(n=225)$ & 0.48 & 0.49 & 0.59 & 0.85 & 0.87 & 0.85 & 0.74 \\
\hline & OC $(n=123)$ & 0.40 & 0.50 & 0.66 & 0.21 & 0.25 & 0.45 & 0.55 \\
\hline & $\mathrm{EC}(n=123)$ & 0.34 & 0.32 & 0.54 & 0.23 & 0.29 & 0.44 & 0.53 \\
\hline \multirow{5}{*}{ Harrow } & Sulphate $(n=426)$ & 0.19 & 0.30 & 0.30 & 0.58 & 0.59 & 0.79 & 0.80 \\
\hline & Nitrate $(n=426)$ & 0.57 & 0.59 & 0.65 & 0.70 & 0.65 & 0.85 & 0.70 \\
\hline & Ammonium $(n=426)$ & 0.22 & 0.22 & 0.25 & 0.44 & 0.57 & 0.70 & 0.76 \\
\hline & OC $(n=227)$ & 0.33 & 0.33 & 0.53 & 0.57 & 0.51 & 0.68 & 0.46 \\
\hline & $\mathrm{EC}(n=227)$ & 0.35 & 0.35 & 0.68 & 0.33 & 0.38 & 0.41 & 0.45 \\
\hline
\end{tabular}

${ }^{\text {a }}$ Raw ATOFMS intensities for sulphate $(\mathrm{m} / \mathrm{z}-97)$, nitrate $(\mathrm{m} / \mathrm{z}-62)$, ammonium $(\mathrm{m} / \mathrm{z} 18)$, OC $(\mathrm{m} / \mathrm{z} 43)$, and EC $(\mathrm{m} / \mathrm{z} 36)$.

$\mathrm{b}$ Total volume of particles corresponding ion intensities.

${ }^{c}$ ATOFMS $_{\mathrm{A}}$ has corresponding ion intensities scaled by APS.

${ }^{\mathrm{d}}$ ATOFMS $_{\mathrm{AF}}$ has corresponding ion intensities scaled by APS and FMPS.

e Number of samples.

in the correlations for sulphate and ammonium. Comparable correlation coefficients have been found when the GPIC has been compared to other high time resolution measurements at other urban and rural sites (Grover et al., 2006; Long and McClenny, 2006; Godri et al., 2009). Grover et al. (2006) found a correlation coefficient (Pearson $r$ ) of 0.82 between the GPIC and R\&P 8400S sulphate instrument. For nitrate, the correlation coefficients between the GPIC and R\&P $8400 \mathrm{~N}$ nitrate measurements were 0.86 in Fresno (Grover et al., 2006), 0.92 in Rubidoux (Long and McClenny, 2006), and 0.86 in Toronto (Godri et al., 2009), all comparable with the scaled ATOFMS value of 0.89 found in this study. However, discrepancies between the measurements occurred for sulphate and ammonium on days with elevated levels of ammonium sulphate and nitrate (23 January and 1 February) in Toronto. There was no discernable association of relative humidity with these discrepancies. As discussed in Fig. 3, relatively poorer hit efficiencies of ATOFMS on these days were already compensated by the scaling factors. During the SPORT campaign in Toronto, Godri et al. (2009) found that the GPIC sulphate on 23 January and the GPIC nitrate on 1 February were slightly higher than the AMS sulphate and R\&P $8400 \mathrm{~N}$ nitrate measurements, respectively, suggesting possible biases on the GPIC measurements on those days.

Continuous sulphate, nitrate, and ammonium concentrations were obtained by the collocated AMS for the BAQSMet study at the rural site in Harrow. The correlation analyses of the ATOFMS and AMS techniques showed that scaled ATOFMS nitrate $(r=0.85)$, sulphate $(r=0.79)$, and ammonium $(r=0.70)$ intensities were well correlated with the corresponding AMS measurements, similar to the SPORT campaign. Comparison of the ATOFMS and the AMS also showed better correlations using scaling based on the APS and FMPS rather than the APS alone. The stronger correlations suggested that using both the FMPS and APS was a more precise way of scaling the ATOFMS data.

The correlation analysis showed that the scaled ATOFMS RPA method in Toronto was a better way than using PA to quantify sulphate, nitrate, and ammonium, whereas there was no consistent improvement of the scaling using RPA in Harrow. The variability in the quantitative ATOFMS methods using RPA and PA reflects that temporally and spatially inhomogeneous particle compositions may influence the sensitivity of the quantification method using single particle mass spectrometry.

The thermal-optical EC concentrations measured by the Sunset OCEC analyzer showed a lower correlation with the scaled ATOFMS ion signal at $\mathrm{m} / z+36$ Daltons $(r=0.41$ to $0.44)$; using the sum of the scaled ATOFMS EC-related ions, $m / z+36,+48$, and +60 , instead did not improve the correlation. It is noteworthy that the determinations of thermaloptical OC and EC concentrations strongly rely on differences in temperature profiles and optical correction methods: thermal-optical transmission (TOT) and thermal-optical reflectance (TOR) (Chow et al., 2001, 2005). The concentrations of EC and OC in this study were determined by the TOT method using a Sunset Lab field OCEC analyzer. Chow et al. $(2001,2005)$ found that EC concentrations using the TOT protocol tend to be lower than the TOR method. During the SPORT campaign, Godri et al. (2009) reported that 

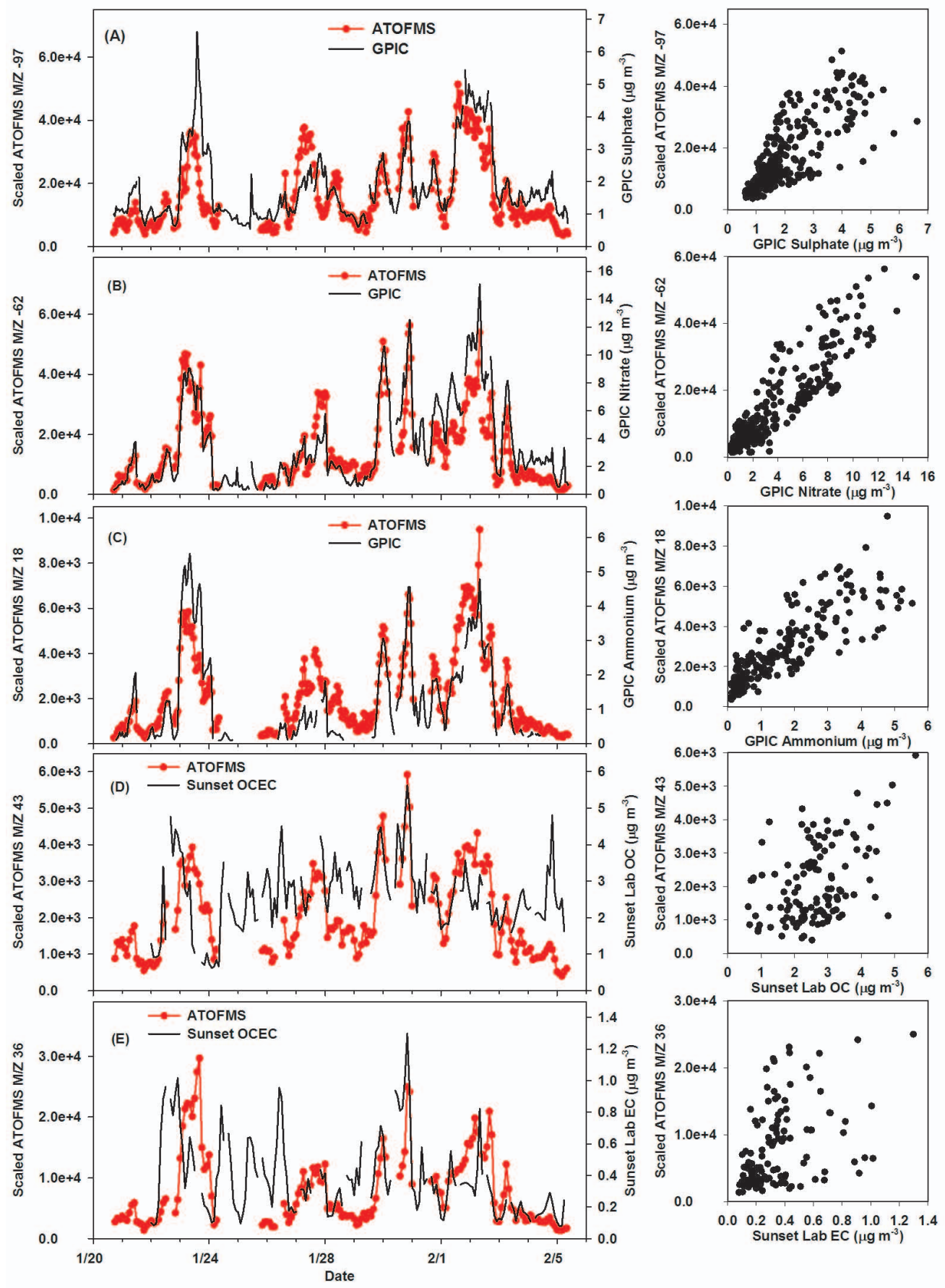

Fig. 4. Comparison between total ATOFMS relative peak area scaled by particle transmission efficiency and corresponding GPIC measurements as well as Sunset Lab OC and EC concentrations during the SPORT campaign in Toronto. (A) sulphate, (B) nitrate, (C) ammonium, (D) OC, and (E) EC.

a comparison of 2-h Sunset OCEC measurements and 24$h$ filter-based analyses showed a weaker correlation for EC than for OC. Another probable explanation for the weak correlation of EC is the incomplete laser desorption and ionization efficiencies of aged particles containing EC coated by OC and inorganic species. Ferge et al. (2006) found that
ATOFMS derived EC and OC values of tunnel dust samples deviated more from the concentrations determined by thermal-optical methods, as compared to EC and OC quantifications for laboratory generated particles. To account for this deviation, they suggested that the increasing fractions of inorganic content in particles increased the uncertainty in the 

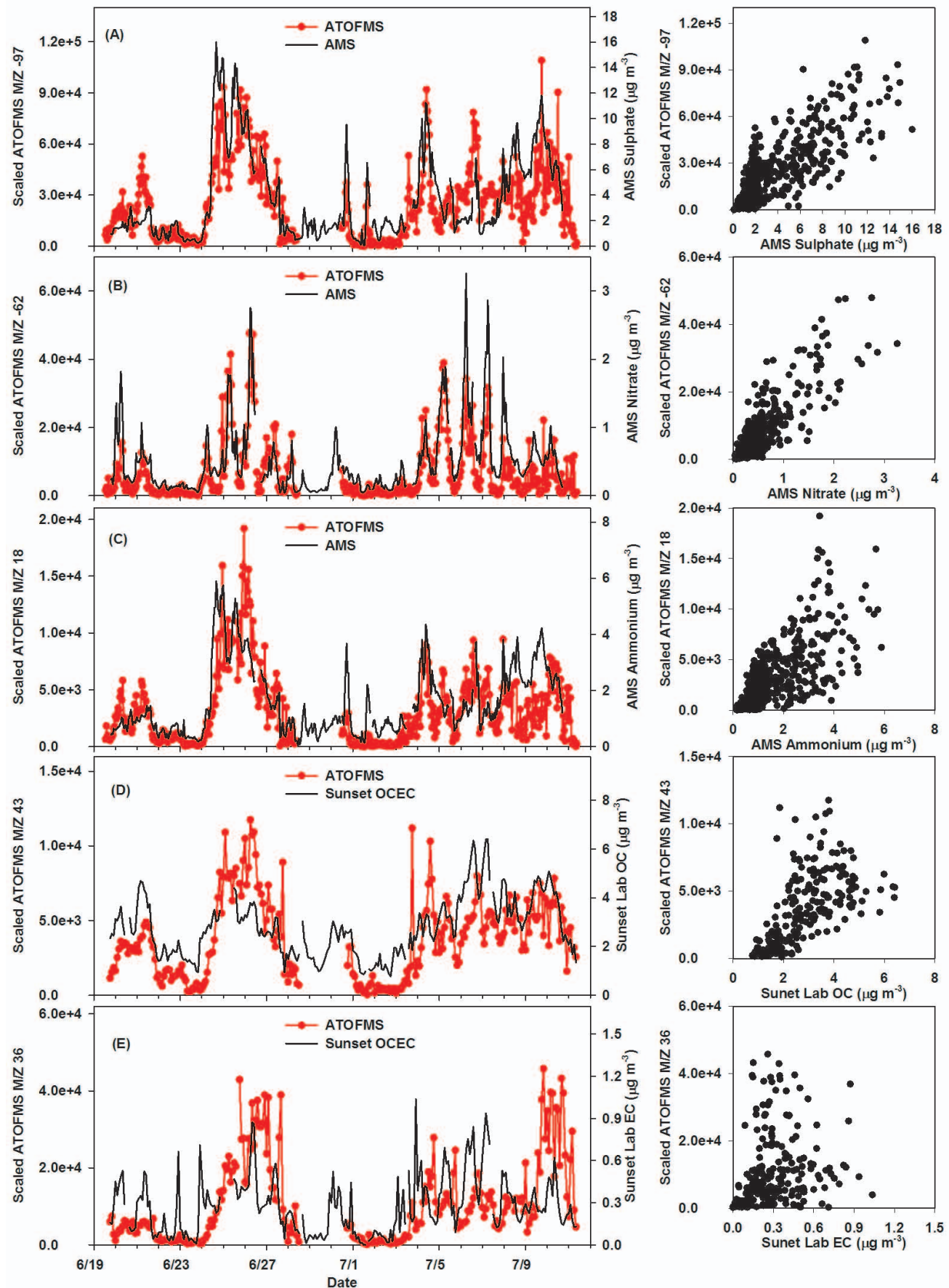

Fig. 5. Comparison between total ATOFMS relative peak area scaled by particle transmission efficiency and corresponding AMS measurements as well as Sunset Lab OC and EC concentrations during the BAQS-Met campaign in Harrow. (A) Sulphate, (B) nitrate, (C) ammonium, (D) OC, and (E) EC.

determination of EC and OC concentrations. Suppression effects of low ionization energy alkali metals (e.g. $\mathrm{Na}^{+}$and $\mathrm{K}^{+}$) on the ion intensities of organic materials have been previously reported by Reilly et al. (2000). Crustal compounds may be more prevalent in ambient particulate matter from rural areas than from a road tunnel. As a result, the estima- tion of carbonaceous material in ambient particles from the ATOFMS single particle mass spectrum data may be biased by the presence of inorganic components. 


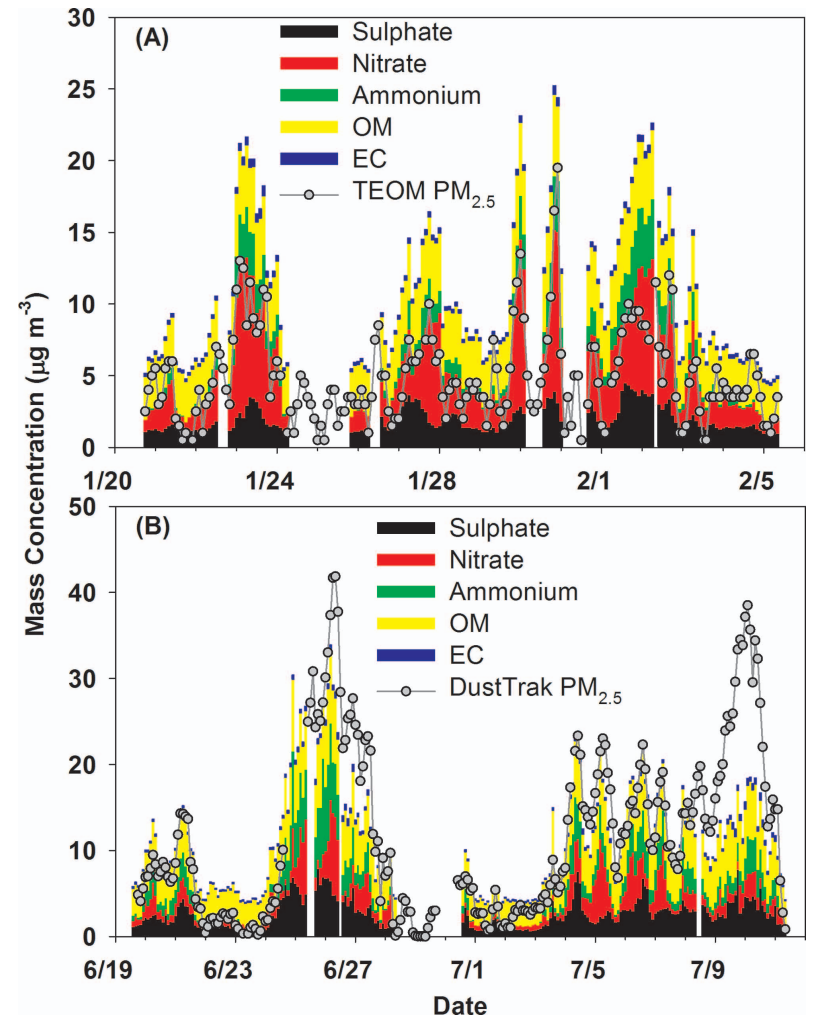

Fig. 6. Stacked two hour resolution chemical species calculated by using scaled ATOFMS RPA and measured $\mathrm{PM}_{2.5}$ mass concentrations by the TEOM in Toronto (A) and the DustTrak in Harrow (B).

\subsection{Mass reconstruction}

Linear regression parameters between the scaled ATOFMS RPA $(V s)$ and the GPIC/Sunset OCEC measurements for each chemical species in Toronto were calculated as presented in Table 3. These mass calibration factors were applied to determine the mass concentrations $\left(\mu \mathrm{g} \mathrm{m}^{-3}\right)$ of corresponding $\mathrm{PM}_{2.5}$ chemical components at both sites. Figure 6 describes the result when the estimated chemical components by the ATOFMS are plotted along with the total $\mathrm{PM}_{2.5}$ mass concentrations measured by the TEOM and the DustTrak in Toronto and Harrow, respectively. In order to account for oxygen and hydrogen, organic matter (OM) was estimated from OC by applying a factor of 1.4 as suggested by Turpin and Lim (2001). Note that the elemental composition of dust was a part of the unaccounted particulate matter mass in this mass reconstruction. On average, nitrate was the largest contributor $(36 \%)$ of the total $\mathrm{PM}_{2.5}$ (sulphate + nitrate + ammonium $+\mathrm{OM}+\mathrm{EC})$ in the winter of Toronto, followed by $\mathrm{OM}(33 \%)$ and sulphate $(18 \%)$. In Harrow, $\mathrm{OM}$, sulphate, and nitrate accounted for approximately $41 \%$, $23 \%$, and $16 \%$ of the $\mathrm{PM}_{2.5}$, respectively. As an agricultural area, the high contributions of $\mathrm{OM}$ and sulphate indicated the strong influence of secondary organic aerosols (SOA) from regional/trans-boundary sources.
Table 3. Mass calibration factors derived from a correlation of the scaled ATOFMS volumetric intensity $\left(\mathrm{Vs}, \mu^{3}\right.$ ) and GPIC/Sunset OCEC measurements $\left(\mu \mathrm{g} \mathrm{m}^{-3}\right)$ for $\mathrm{PM}_{2.5}$ chemical components during the SPORT campaign (parameter values \pm standard errors).

\begin{tabular}{lcc}
\hline & \multicolumn{1}{c}{ Slope $(\alpha)$} & Intercept $(\beta)$ \\
\hline $\begin{array}{l}\text { Sulphate }^{\mathrm{a}} \\
\left(\mathrm{m} / \mathrm{z}^{-97)}\right.\end{array}$ & $8.14 \times 10^{-5} \pm 3.19 \times 10^{-6}$ & $5.86 \times 10^{-1} \pm 6.21 \times 10^{-2}$ \\
$\begin{array}{l}\text { Nitrate }^{\mathrm{a}} \\
\left(\mathrm{m} / \mathrm{z}^{-62)}\right.\end{array}$ & $2.28 \times 10^{-4} \pm 6.61 \times 10^{-6}$ & $3.47 \times 10^{-1} \pm 1.29 \times 10^{-1}$ \\
$\begin{array}{l}\text { Ammonium } \\
\left(\mathrm{m} / \mathrm{z}_{18}\right.\end{array}$ & $6.47 \times 10^{-4} \pm 2.46 \times 10^{-5}$ & $-2.55 \times 10^{-1} \pm 7.90 \times 10^{-2}$ \\
$\begin{array}{l}\mathrm{OC}^{\mathrm{b}} \\
\left(\mathrm{m} / \mathrm{z}_{4} 43\right)\end{array}$ & $3.83 \times 10^{-4} \pm 6.88 \times 10^{-5}$ & $1.80 \times 10^{0} \pm 1.65 \times 10^{-1}$ \\
$\begin{array}{l}\mathrm{EC}^{\mathrm{b}} \\
(\mathrm{m} / \mathrm{z} 36)\end{array}$ & $1.74 \times 10^{-5} \pm 3.21 \times 10^{-6}$ & $2.12 \times 10^{-1} \pm 3.18 \times 10^{-2}$ \\
\hline
\end{tabular}

$\mathrm{a}[\mathrm{GPIC}]=\alpha \cdot V_{\mathrm{S}}+\beta$.

${ }^{b}[$ Sunset OCEC $]=\alpha \cdot V_{\mathrm{S}}+\beta$.

The reconstructed mass (sulphate + nitrate + ammonium $+\mathrm{OM}+\mathrm{EC}$ ) from the scaled ATOFMS data correlated well with the total $\mathrm{PM}_{2.5}$ mass $(r=0.86$ for Toronto, $r=0.87$ for Harrow). In Toronto, the regression between the total ATOFMS $(y)$ and TEOM $(x)$ measurements indicated a slope of 1.33 with an intercept of 3.81. Much of this difference was due to the loss of semi-volatile material in the TEOM monitor. Due to a strong winter-high seasonality of nitrate formation, the heated TEOM monitor volatilizes a significant portion of the PM mass (i.e. ammonium nitrate and semivolatile organics) in wintertime (Schwab et al., 2004, 2006). As shown in Fig. 6a, on the days of high ammonium nitrate, i.e. 23 January and 1 February 2007, the discrepancy tended to increase. Further, $68 \%$ of the $\mathrm{PM}_{2.5}$ was on average present as organic mass or nitrate, components that could potentially volatilize in the TEOM. The negative bias in the TEOM were also previously reported during winter at this Toronto site, using reconstructed mass concentrations based on 24-h filter measurements or 2-h GPIC plus OCEC data (Godri et al., 2009).

For Harrow comparison of the reconstructed ATOFMS data ( $y)$ and the DustTrak $\mathrm{PM}_{2.5}$ measurements $(x)$ yielded a slope of 0.52 with an intercept of 4.62. At the lower $\mathrm{PM}_{2.5}$ concentration range $\left(<10 \mu \mathrm{g} \mathrm{m}^{-3}\right)$ the DustTrak $\mathrm{PM}_{2.5}$ tended to be lower than the reconstructed ATOFMS, whereas the DustTrak data exceeded the ATOFMS data as the $\mathrm{PM}_{2.5}$ mass increased at the higher concentration range above $10 \mu \mathrm{g} \mathrm{m}^{-3}$. As shown in Fig. $6 \mathrm{~b}$, the largest discrepancy was observed during 9-10 July. Particle size distribution data from the FMPS and APS indicated this difference was associated with an increase in particles larger than $0.6 \mu \mathrm{m}$. During 9-10 July, there was a distinct difference between the AMS sulphate, nitrate, ammonium, and organic mass concentrations and the DustTrak $\mathrm{PM}_{2.5}$ mass concentrations (Fig. S3). The presence of refractory materials 
(elemental carbon and soil dust) could be a possible reason for the absence of AMS mass measurements, since the AMS is unable to detect those PM components. In addition, the comparison between the DustTrak measurements and scaled volume concentrations measured by ATOFMS under the assumption of RPA of 1 showed excellent agreement, suggesting that obtaining scaling factors in this study using two particle number concentration measurements was effective. The average values of RPA for sulphate, nitrate, ammonium, and OC during 9-10 July were $15-35 \%$ lower than these averages during the entire measurement period, whereas the RPA for EC was approximately $70 \%$ higher than the average value. However, the presence of EC could not substantially contribute to the total $\mathrm{PM}_{2.5}$ mass concentrations due to the relatively smaller mass calibration factor as shown in Table 3. In addition to the increase of the RPA values for EC $(\mathrm{m} / \mathrm{z} \pm 12, \pm 24, \pm 36, \pm 48, \pm 60)$ in the positive and negative mass spectra, more dust related ion spectra from phosphate $(\mathrm{m} / \mathrm{z}-47,-63,-79,-95)$, sodium $(\mathrm{m} / \mathrm{z} 23)$, calcium $(\mathrm{m} / \mathrm{z}, 40,56)$, and iron $(\mathrm{m} / \mathrm{z} 54,56)$ were detected in large particles $(>0.6 \mu \mathrm{m})$ (Fig. S4). These results imply that the most likely factor causing disagreement in mass concentrations from the DustTrak and ATOFMS during the 9-10 July event would be the presence of crustal materials, which the mass reconstruction of ATOMFS did not include. Moderately high relative humidity $(\sim 88 \%)$ was observed at the peak time (04:00 a.m. LT, 10 July) of the event with a mean $\mathrm{RH}$ of $65 \pm 15 \%$ during the event. The high relative humidity over the night would be another factor that introduces the maximum differences at night. Significant amounts of water on the particle surface may lead to decreasing ion intensities of sulphate and nitrate due to the deliquescence of ammonium nitrate/ammonium sulphate (Ge et al., 1998). Some uncertainties to this comparison may result from the strong effect of RH on aerosol light scattering (Carrico et al. 1998). The high RH during the nighttime can cause $\mathrm{PM}_{2.5}$ readings of DustTrak using a light scattering technology to be biased.

Excluding 9-10 July, the averages of the two measurements agreed almost perfectly, however, a recovery of 0.86 (i.e. slope with the intercept $=0$ ) was obtained due to differences at low and high concentrations. This agreement must be emphasized as the Harrow ATOFMS mass reconstruction was calculated based on calibration factors derived from the Toronto data, collected in winter not summer and at an urban instead of a rural site. Thus it appears that it may be possible to extend calibration factors from one site to another such that mass concentrations can be estimated from ATOFMS data even when no other co-located speciation instrumentation is available.

It is recommended that this approach to mass reconstruction, based on ATOFMS data, be further explored using data from additional sites, in order to better establish if or when calibration factors can in general be applied to multiple sites. In addition, more work is required in the estimation of the carbonaceous species. The correlation of the scaled ATOFMS and the Sunset OCEC measurements were poorer than the other three chemical species, sulphate, nitrate, and ammonium, thus the estimated OM and EC masses had higher uncertainties.

\subsection{Scaling ATOFMS particle-types}

The size-scaling and mass-calibration-factor methodology was also used in order to estimate the mass composition of different types of particles. The contribution of the 10 particle-types to the total detected particles and the most representative ions for each particle-type are presented in Table 4. A more detailed explanation for the particle-types is provided elsewhere (McGuire et al., 2011). Figure 7 exhibits the number fraction of these particle-types as a function of particle diameter. In this clustering analysis, the number and size distributions of particles smaller than $0.5 \mu \mathrm{m}$ were combined into one size bin. The 10 particle-types were scaled by the hourly size-specific scaling factors. Equation (5) was applied to each individual particle of a given particle-type, to estimate hourly scaled volumetric intensities of the five major chemical components for that particle-type. In this quantification method, the mass calibration factors in Table 3 were used to convert the scaled volume intensities into mass concentrations $\left(\mu \mathrm{g} \mathrm{m}^{-3}\right)$. The average mass concentration of the five chemical species and their contributions to the 10 particle-types are depicted in Fig. 8. It should be noted that, the mass concentrations and compositions in Fig. 8 are with respect to the five major chemical components. These five components represented the majority of the overall $\mathrm{PM}_{2.5}$ mass, and thus presumably the majority of the mass for each particle-type. However, not all particle components detected by the ATOFMS were used for the mass closure, thus Fig. 8 does not necessarily represent a complete mass reconstruction. Most of the particle-types contain at least some of all five components, indicating a high degree of internal mixing of these components. This is not surprising given that four of the five components were presumably secondary in nature, with EC representing the only primary component. In terms of these five components, the particle-types differed mostly in their relative ratios of sulphate or nitrate to ammonium, and organic to elemental carbon. The degree of external mixing of the minor components, not shown here, was greater.

The mass concentrations (Fig. 8) of the particle-types was also used to estimate their acidity ratio, the molar ratio of ammonium to nitrate + sulphate: $\left(\left[\mathrm{NH}_{4}^{+}\right] / 18\right) /(2 \times$ $\left.\left[\mathrm{SO}_{4}^{2-}\right] / 96+\left[\mathrm{NO}_{3}^{-}\right] / 62\right)$. On average, particle acidity analysis using the scaled mass concentrations showed that more than half $(61 \%)$ of total particle mass concentration in Harrow were neutralized or slightly acidic with an acidity ratio of $0.75 \pm 0.29$ (mean \pm standard deviation). The acidity ratios were generally within the expected range of 0.5 to 1.0 , providing a further measure of the accuracy of the composition estimated for these particles. A previous aerosol acidity study using 5-yr data from filter samples reported that the 
Table 4. Major ion markers of the 10 major particle types in Harrow.

\begin{tabular}{|c|c|}
\hline Particle Types & Major Ions \\
\hline OC-S & ${ }^{18} \mathrm{NH}_{3}^{+},{ }^{43} \mathrm{C}_{3} \mathrm{H}_{7}^{+} / \mathrm{C}_{2} \mathrm{H}_{3} \mathrm{O}^{+} / \mathrm{CHNO}^{+},{ }^{97} \mathrm{HSO}_{4}^{-}$ \\
\hline OC-S-N & ${ }^{18} \mathrm{NH}_{3}^{+},{ }^{43} \mathrm{C}_{3} \mathrm{H}_{7}^{+} / \mathrm{C}_{2} \mathrm{H}_{3} \mathrm{O}^{+} / \mathrm{CHNO}^{+},{ }^{26} \mathrm{CN}^{-},{ }^{4}{ }^{46} \mathrm{NO}_{2}^{-},{ }^{62} \mathrm{NO}_{3}^{-},{ }^{97} \mathrm{HSO}_{4}^{-}$ \\
\hline $\mathrm{OC}$ & ${ }^{27} \mathrm{C}_{2} \mathrm{H}_{3}^{+},{ }^{39} \mathrm{~K}^{+},{ }^{43} \mathrm{C}_{3} \mathrm{H}_{7}^{+} / \mathrm{C}_{2} \mathrm{H}_{3} \mathrm{O}^{+} / \mathrm{CHNO}^{+},{ }^{97} \mathrm{HSO}_{4}^{-}$ \\
\hline EC-OC & ${ }^{12} \mathrm{C}_{2}^{+},{ }^{36} \mathrm{C}_{3}^{+},{ }^{97} \mathrm{HSO}_{4}^{-}$ \\
\hline Amines & ${ }^{59} \mathrm{C}_{3} \mathrm{H}_{9} \mathrm{~N}^{+}$ \\
\hline Fireworks & ${ }^{39} \mathrm{~K}^{+},{ }^{154} \mathrm{BaOH}+,{ }^{46} \mathrm{NO}_{2}^{-},{ }^{62} \mathrm{NO}_{3}^{-},{ }^{163} \mathrm{~K}\left(\mathrm{NO}_{3}\right){ }_{2}^{-},{ }^{125} \mathrm{H}\left(\mathrm{NO}_{3}\right)_{2}^{-}$ \\
\hline $\mathrm{EC}(\mathrm{I})$ & ${ }^{12 n} \mathrm{C}_{n}^{ \pm},{ }^{23} \mathrm{Na}^{+}$ \\
\hline $\mathrm{EC}$ (II) & ${ }^{12 n} \mathrm{C}_{n}^{ \pm},{ }^{39} \mathrm{~K}^{+},{ }^{46} \mathrm{NO}_{2}^{-},{ }^{62} \mathrm{NO}_{3}^{-},{ }^{97} \mathrm{HSO}_{4}^{-}$ \\
\hline Dust & ${ }^{23} \mathrm{Na}^{+},{ }^{39} \mathrm{~K}^{+},{ }^{40} \mathrm{Ca}^{+},{ }^{56} \mathrm{CaO}^{+},{ }^{16} \mathrm{O}^{-},{ }^{17} \mathrm{OH}^{-},{ }^{46} \mathrm{NO}_{2}^{-},{ }^{62} \mathrm{NO}_{3}^{-}$ \\
\hline Dust-Na & ${ }^{23} \mathrm{Na}^{+},{ }^{16} \mathrm{O}^{-},{ }^{17} \mathrm{OH}^{-},{ }^{46} \mathrm{NO}_{2}^{-},{ }^{62} \mathrm{NO}_{3}^{-},{ }^{131} \mathrm{NaNO}_{2} \mathrm{NO}_{3}^{-}$ \\
\hline
\end{tabular}

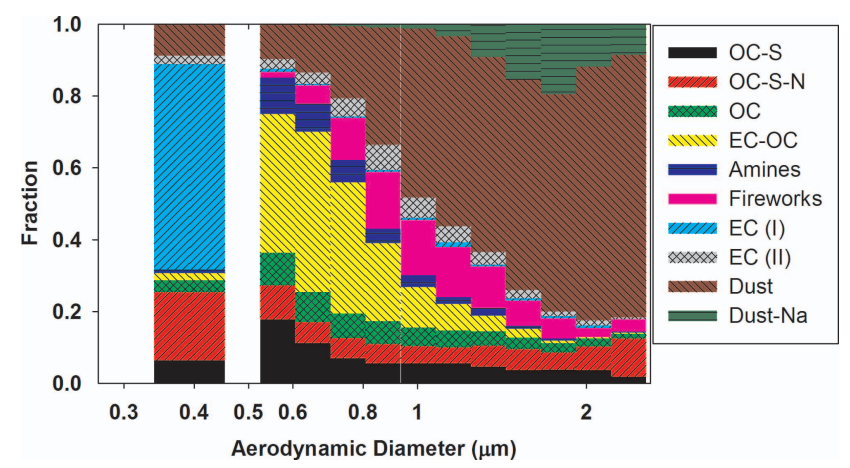

Fig. 7. The proportion of particles of each type, based on particle number, as a function of particle size.

aerosol molar ratio ranged from 0.75 to 0.98 during summer months while more than $97 \%$ of samples had a ratio between 0.5 and 1.0 at a rural site in the northeastern United States (Ziemba et al., 2007). However, acidity ratios above 1.0 were found for some particle types, suggesting that errors remained in the estimation of some of the associated components. Thus the trends in the acidity ratios rather than their absolute values were used to compare the acidity of the particle-types.

The OC-S was the largest contributor (30\%) to the total mass concentration measured by the ATOFMS, followed by the OC-S-N (29\%). In addition, these two particle-types explained the majority (54-63\%) of the sulphate, nitrate, ammonium, and OC in Harrow (Table 5). The OC-S particles were composed of similar amounts of organic and inorganic components, with sulphate and ammonium making up most of the inorganic mass. This corresponded to the strong sulphate $(\mathrm{m} / \mathrm{z}-97)$ and ammonium $(\mathrm{m} / \mathrm{z}, 18)$ in the mass spectra of the OC-S particles peaks, with the presence of high $\mathrm{m} / \mathrm{z}$ organic peaks. The OC-S-N particles had similar composition but with more nitrate. Their spectra contained strong organic fragment peaks (i.e. $\mathrm{m} / \mathrm{z} 27$ and 43) mixed with load- ings of organic nitrogen compounds $\left(\mathrm{m} / z-26\left[\mathrm{CN}^{-}\right]\right.$and $\left.-42\left[\mathrm{CNO}^{-}\right]\right)$.

The acidity ratios for the OC-S-N and OC-S particle-types were 0.91 and 1.42 , respectively, indicating that the OC-S-N particles were more acidic than the OC-S. This is consistent with the presence of more nitrate in the OC-S-N particletype. While the OC-S-N types were observed throughout the whole campaign, the OC-S particles were mostly detected during the later period of the campaign (5 to 6 July), when more organic mass was present.

The OC-rich particle-type contained a large amount of organic mass and contributed $\sim 16 \%$ of the total mass, measured by the ATOFMS at the Harrow site. The OC-rich particles were similar in composition to the OC-S particles except that their mass spectra contained a much larger $\mathrm{K}^{+}$peak. The presence of potassium in particle mass spectra has previously been found to be a good marker of biomass burning (Bein et al., 2008). Further these particles had a relatively small mode in their size distribution at $\sim 0.45 \mu \mathrm{m}$, suggesting that this potassium did not originate from soil road dust. The OC-rich particles had an acidity ratio of 0.87 and thus were more acidic than the other OC particle-types.

The EC-OC particles contained much $(42 \%)$ of the elemental carbon and had a high ratio of elemental to organic carbon (Table 5). The spectra of the EC-OC particles had clear EC peaks at $m / z \pm 12$ and \pm 36 and organic fragments with $m / z-97$ ion peaks. This type contributed $11 \%$ of the total mass detected by the ATOFMS. The EC-OC was the most abundant particle-type on a particle number basis.

The amine and fireworks particle-types were only observed on certain days. For example, a large number of fireworks particles were observed on 5 July, the day after the 4 July celebration. The fireworks particles contained large amounts of nitrate, possibly as residue from the $\mathrm{KNO}_{3}$ used in the gun powder. The mass spectra of the fireworks particletype were characterized by strong $\mathrm{Mg}^{+}, \mathrm{K}^{+}$, and nitrate with the presence of $m / z 88\left[\mathrm{Sr}^{+}\right], m / z 154\left[\mathrm{BaOH}^{+}\right]$, and $m / z$ 
Table 5. Contribution (\%) of the 10 particle types to $\mathrm{PM}_{2.5}$ major chemical components in Harrow.

\begin{tabular}{lccccc}
\hline Particle Types & Sulphate & Nitrate & Ammonium & OM $^{*}$ & EC \\
\hline OC-S & 33 & 21 & 36 & 31 & 15 \\
OC-S-N & 29 & 34 & 24 & 30 & 15 \\
OC & 15 & 15 & 11 & 19 & 8 \\
EC-OC & 16 & 10 & 11 & 6 & 43 \\
Amines & 3 & 7 & 11 & 8 & 3 \\
Fireworks & 0 & 2 & 0 & 0 & 0 \\
EC (I) & 1 & 0 & 5 & 2 & 13 \\
EC (II) & 1 & 1 & 1 & 1 & 3 \\
Dust & 1 & 9 & 1 & 4 & 1 \\
Dust-Na & 0 & 1 & 0 & 0 & 0 \\
\hline
\end{tabular}

$* \mathrm{OM}=1.4 \times \mathrm{OC}$.

Estimates presented are subject to rounding errors.

$-163\left[\mathrm{~K}\left(\mathrm{NO}_{3}\right)_{2}^{-}\right]$. Previous studies also found $\mathrm{K}, \mathrm{Al}, \mathrm{Mg}$, $\mathrm{Ba}$, and $\mathrm{Sr}$ are key elements of fireworks (e.g. Liu et al., 1997; Moreno et al., 2007). Although the mass contribution of the fireworks particle type was negligible, this type had a very low acidity ratio of 0.2 . This low ratio was consistent with the nitrate being associated with alkaline earth compounds (e.g. $\mathrm{KNO}_{3}$ ) rather than ammonium and thus was likely not indicative of high acidity. The amine type contained a high abundance of organic matter and more nitrate than sulphate. The presence of amine was identified by a peak at $\mathrm{m} / \mathrm{z} 59$ $\left[\mathrm{C}_{3} \mathrm{H}_{9} \mathrm{~N}\right]$. OC fragments and low negative ion peaks were also observed in the mass spectra. While the amine particletype accounted for $7 \%$ of the total mass measured by the ATOFMS, the type was only observed during periods of high relative humidity (Rehbein et al., 2011). Amines in ambient aerosols have been identified at a variety of locations using single particle mass spectrometers (e.g. Ge et al., 2011). Angelino et al. (2001) found that amine particles characterized by $m / z 86$ increased with increasing RH and decreasing temperature in urban areas.

The EC (I) and EC (II) particles contained high proportions of elemental carbon. The mass spectra of the EC (I) particles had clear $\mathrm{C}_{12 n}^{ \pm}$fragment peaks (e.g. $m / z \pm 12, \pm 24$, \pm 36 ) and a strong $\mathrm{Na}^{+}$peak at $\mathrm{m} / z, 23$ while those for the EC (II) type also had higher sulphate and nitrate intensities with the $\mathrm{C}_{12 n}^{ \pm}$fragment peaks. The size distribution of the EC (I) type exhibited the small mode at $\sim 0.25 \mu \mathrm{m}$. The small size and low sulphate to elemental carbon ratio suggested that these particle types were associated with fresh emissions from fossil combustion processes. The EC (I) type was observed in other ATOFMS studies at different locations (Dall'Osto et al., 2006; Moffet et al., 2008). These single particle analysis studies found that the early morning peak of an EC particle type with high intensities of $\mathrm{Na}^{+}$was associated with freshly emitted vehicle particles. The larger size mode $(0.84 \mu \mathrm{m})$ of the EC (II) type and the presences of sul-

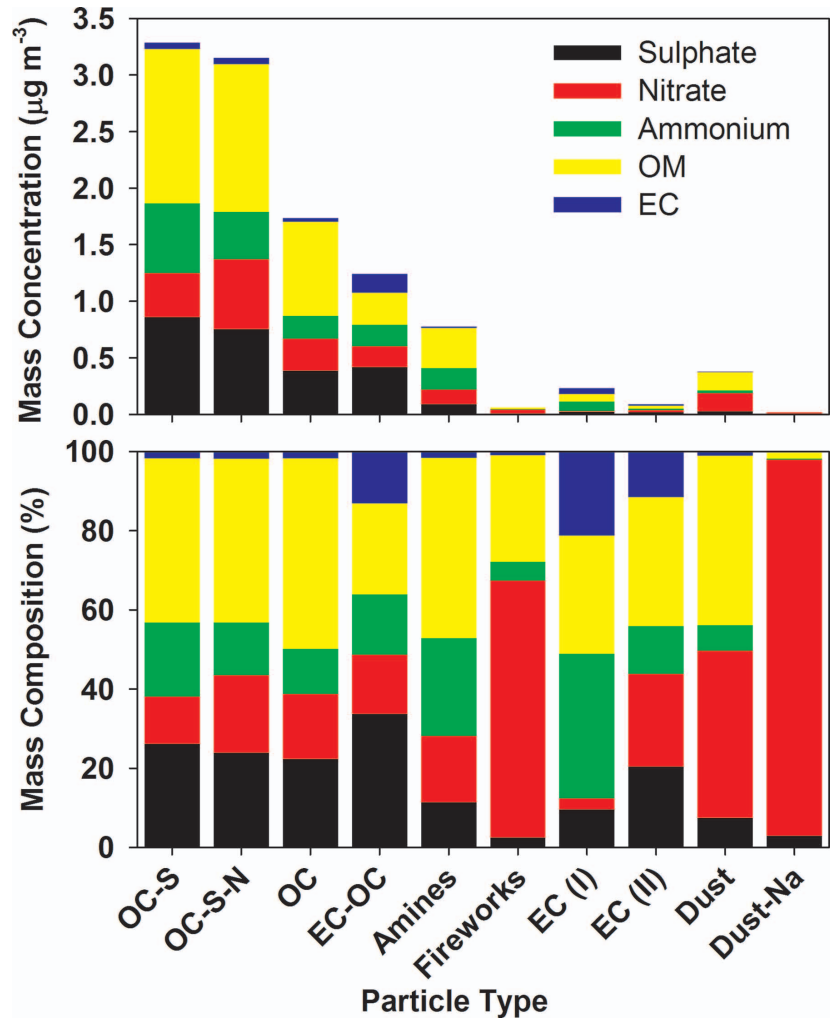

Fig. 8. Average mass concentration (A) and composition (B) of the five $\mathrm{PM}_{2.5}$ chemical components in the 10 particle types.

phate and nitrate peaks suggested that this particle-type was associated with aging. The EC (II) particles may have been a more processed version of the EC (I) particles.

Two dust-related types (Dust, Dust-Na) were found with relatively larger modes $(>0.8 \mu \mathrm{m})$ in their size distributions with the common presence of $m / z-16$ and -17 as well as peaks at $m / z-46$ and 23. The Dust type was characterized by strong crustal element peaks at $\mathrm{m} / z 24\left[\mathrm{Mg}^{+}\right]$, $27\left[\mathrm{Al}^{+}\right], 39\left[\mathrm{~K}^{+}\right], 56\left[\mathrm{CaO}^{+}\right]$mixed with more organic fragments, whereas the Dust-Na type was more clearly associated with $\mathrm{Na}^{+}$and fragments (e.g. $131\left[\mathrm{NaNO}_{2} \mathrm{NO}_{3}^{-}\right]$, $\left.147\left[\mathrm{Na}\left(\mathrm{NO}_{3}\right)_{2}^{-}\right]\right)$of sodium nitrate. Of the five compounds quantified, nitrate was the most important contributor to the mass of the dust related particle-types (Fig. 8b); other compounds not quantified from the ATOFMS data, such as mineral oxides, likely also contributed. The contribution of these compounds is not reflected in Fig. 8. The low content of ammonium indicated an internal mixture of nitrate and mineral dust components, possibly $\mathrm{CaNO}_{3}$ and $\mathrm{NaNO}_{3}$. The reactions of $\mathrm{HNO}_{3}$ with $\mathrm{NaCl}$ or $\mathrm{CaCO}_{3}$ are well-known depletion mechanisms of $\mathrm{HNO}_{3}$ in the atmosphere (Myhre et al., 2006). The dust group particles were mostly larger in size; the Dust-Na cluster showed the largest size distribution with a mode of $1.8 \mu \mathrm{m}$. 
It should be emphasized that the reported compositions are estimates and the methodology still requires refinement. Specifically, implicit in the approach was the assumption that compounds exhibited similar sensitivities within different particle-types. This assumption needs to be further investigated.

\section{Conclusions}

Mass concentrations of $\mathrm{PM}_{2.5}$ chemical components were determined from ATOFMS data collected at urban and rural sites during the SPORT and BAQS-Met field campaigns. In order to account for the temporal changes in the particle detection efficiency of the ATOFMS, the ATOFMS data were scaled using particle number concentrations measured simultaneously by an APS and an FMPS. Hourly scaled volume concentrations of the five chemical species were estimated using the ATOFMS relative peak area (RPA) and these hourly size-specific scaling factors. This approach allowed sulphate, nitrate, ammonium, OC, and EC mass concentrations to be derived for the first time based on real-time single particle ATOFMS measurements. Sensitivity analysis was performed by comparing this approach to results obtained using peak area (PA) instead (i.e. PA vs. RPA), as well as results obtained using only the APS for scaling (i.e. APS alone vs. APS + FMPS). This sensitivity analysis further validated the approach selected.

During the SPORT campaign in Toronto, nitrate $(r=0.89)$ showed the strongest correlation between the ATOFMS and parallel GPIC measurements. Good correlations were also observed for ammonia $(r=0.85)$ and sulphate $(r=0.79)$ in the urban area. The correlation analyses for the BAQS-Met study in Harrow also showed good correlations between the ATOFMS measurements and continuous nitrate $(r=0.85)$, sulphate $(r=0.79)$, and ammonium $(r=0.70)$ measured by a collocated AMS. Comparisons of OC and EC derived from the ATOFMS and a Sunset OCEC analyzer showed weaker correlations at the two sites.

Linear regression coefficients derived from the Toronto site were applied to both the Toronto and Harrow ATOFMS data in order to estimate the mass concentrations of the corresponding $\mathrm{PM}_{2.5}$ chemical components. The reconstructed mass concentrations from the scaled ATOFMS were well correlated with continuous $\mathrm{PM}_{2.5}$ measurements in the urban area (Toronto, $r=0.86, p<0.05$ ) and the rural area (Harrow, $r=0.87, p<0.05)$. In the urban area nitrate was the largest contributor $(\sim 36 \%)$ to the total $\mathrm{PM}_{2.5}$ in the winter, followed by OM $(\sim 33 \%)$ and sulphate $(\sim 18 \%)$. During the summertime, $\mathrm{PM}_{2.5}$ in the rural area near the US border in southern Ontario was strongly influenced by regional/transboundary pollution resulting in a greater abundance of OM $(\sim 41 \%)$ and sulphate $(\sim 23 \%)$. The ATOFMS reconstructed mass for Harrow was based on regression parameters derived from Toronto data yet still agreed reasonably well with total mass measurements made at the Harrow site. Thus it appears that it may be possible to extend regression parameters from one site to another such that mass concentrations can be estimated from ATOFMS data even when no other co-located speciation instrumentation is available.

Ten major particle-types: OC-S, OC-S-N, OC-rich, ECOC, Amines, Fireworks, EC (I), EC (II), Dust, Dust-Na were identified by applying the ART-2a clustering algorithm to ATOFMS ion mass spectra data collected from Harrow. The number and size distributions of the 10 particle-types were scaled by the hourly size-specific scaling factors. The scaling significantly altered the size distributions and contributions of the particle-types. The quantification approach was also applied to scaled mass spectra of each particle-type so as to calculate the mass composition of each particle-type in terms of their major components. This approach provided new insight into the contribution made by different particle-types to the overall mass composition.

\section{Supplementary material related to this article is available online at: http://www.atmos-chem-phys.net/11/7027/2011/ acp-11-7027-2011-supplement.pdf.}

Acknowledgements. This work was supported by in part by the Ontario Ministry of the Environment and Environment Canada. Funding for SOCAAR was provided by the Canada Foundation for Innovation, the Ontario Innovation Trust and the Ontario Research Fund. The authors would like to thank Andrew Knox for OC and EC instrument operation at the Toronto site.

Edited by: D. Hastie

\section{References}

Allen, J. O., Fergenson, D. P., Gard, E. E., Hughes, L. S., Morrical, B. D., Kleeman, M. J., Gross, D. S., Galli, M. E., Prather, K. A., and Cass, G. R.: Particle detection efficiencies of aerosol time of flight mass spectrometers under ambient sampling conditions, Environ. Sci. Technol., 34, 211-217, 2000.

Angelino, S., Suess, D. T., and Prather, K. A.: Formation of aerosol particles from reactions of secondary and tertiary alkylamines: Characterization by aerosol time-of-flight mass spectrometry, Environ. Sci. Technol., 35, 3130-3138, 2001.

Armendariz, A. J. and Leith, D.: Concentration measurement and counting efficiency for the aerodynamic particle sizer 3320 , J. Aerosol Sci., 33, 133-148, 2002.

Ault, A. P. Moore, M. J. Furutani, H., and Prather, K. A.: Impact of emissions from the Los Angeles port region on San Diego air quality during regional transport events, Environ. Sci. Technol., 43, 3500-3506, 2009.

Beddows, D. C. S., Donovan, R. J., Harrison, R. M., Heal, M. R., Kinnersley, R. P., King, M. D., Nicholson, D. H., and Thompson, K. C.: Correlations in the chemical composition of rural background atmospheric aerosol in the UK determined in real time 
using time-of-flight mass spectrometry, J. Environ. Monitor., 6 , 124-133, 2004.

Bein, K. J., Zhao, Y., Pekney, N. J., Davidson, C. I., Johnston, M. V., and Wexler, A. S.: Identification of sources of atmospheric PM at the Pittsburgh Supersite - Part II: quantitative comparisons of single particle, particle number, and particle mass measurements, Atmos. Environ., 40, S424-S444, 2006.

Bein, K. J., Zhao, Y., Johnston, M. V., Evans, G. J., and Wexler A. S.: Extratropical waves transport boreal wildfire emissions and drive regional air quality dynamics, J. Geophys. Res., 113, D23213, doi:10.1029/2008JD010169, 2008.

Bhave, P. V., Allen, J. O., Morrical, B. D., Fergenson, D. P., Cass G. R., and Prather, K. A.: A field-based approach for determining ATOFMS instrument sensitivities to ammonium and nitrate, Environ. Sci. Technol., 36, 4868-4879, 2002.

Burnett, R. T., Dales, R., Krewski, D., Vincent, R., Dann, T., and Brook, J. R.: Associations between ambient particulate sulfate and admissions to Ontario hospitals for cardiac and respiratory diseases, Am. J. Epidemiol., 172, 15-22, 1995.

Carrico, C. M., Rood, M. J., and Ogren, J. A.: Aerosol light scattering properties at Cape Grim, Tasmania, during the First Aerosol Characterization Experiment (ACE 1), J. Geophys. Res., 103(D13), 16565-16574, 1998.

Chow, J. C., Watson, J. G., Crow, D., Lowenthal, D. H., and Merrifield, T.: Comparison of IMPROVE and NIOSH carbon measurements, Aerosol Sci. Technol., 34, 23-34, 2001.

Chow, J. C., Watson, J. G., Chen, L.-W. A., Paredes-Miranda, G., Chang, M.-C. O., Trimble, D., Fung, K. K., Zhang, H., and Zhen Yu, J.: Refining temperature measures in thermal/optical carbon analysis, Atmos. Chem. Phys., 5, 2961-2972, doi:10.5194/acp5-2961-2005, 2005.

Dall'Osto, M. and Harrison, R. M.: Chemical characterisation of single airborne particles in Athens (Greece) by ATOFMS, Atmos. Environ., 40, 7614-7631, 2006.

Dall'Osto, M., Harrison, R. M., Beddows, D. C. S., Freney, E. J., Heal, M. R., and Donovan, R. J.: Single-particle detection efficiencies of aerosol time-of-flight mass spectrometry during the North Atlantic marine boundary layer experiment, Environ. Sci. Technol., 40, 5029-5035, 2006.

Dockery, D. W., Pope, A., Xu, X., Spengler, J. D., Ware, J. H., Fay, M. E., Ferris, M. G., and Speizer, F. E.: An association between air pollution and mortality in six U.S. cities, N. Engl. J. Med., 329, 1753-1759, 1993.

Ferge, T., Karg, E., Schröppel, A., Coffee, K. R., Tobias, H. J., Frank, M., Gard, E. E., and Zimmermann, R.: Fast determination of the relative elemental and organic carbon content of aerosol samples by on-line single-particle aerosol time-of-flight mass spectrometry, Environ. Sci. Technol., 40, 3327-3335, 2006.

Gard, E., Mayer, J. E., Morrical, B. D., Dienes, T., Fergenson, D. P., and Prather, K. A.: Real-time analysis of individual atmospheric aerosol particles: design and performance of a portable ATOFMS, Anal. Chem., 69, 4083-4091, 1997.

Ge, Z., Wexler, A. S., and Johnston, M. V.: Deliquescence behavior of multicomponent aerosols, J. Phys. Chem. A., 102, 173-180, 1998.

Ge, X., Wexler, A. S., and Clegg, S. L.: Atmospheric amines - Part I: a review, Atmos. Environ., 45, 524-546, 2011.

Godri, K. J., Evans, G. J., Slowik, J., Knox, A., Abbatt, J., Brook, J., Dann, T., and Dabek-Zlotorzynska, E.: Evaluation and ap- plication of a semi-continuous chemical characterization system for water soluble inorganic PM2.5 and associated precursor gases, Atmos. Meas. Tech., 2, 65-80, doi:10.5194/amt-2-652009, 2009.

Gross, D. S., Galli, M. E., Silva, P. J., and Prather, K. A.: Relative sensitivity factors for alkali metal and ammonium cations in single-particle aerosol time-of-flight mass spectra, Anal. Chem., 72, 416-422, 2000.

Grover, B. D., Eatough, N. L., Eatough, D. J., Chow, J. C., Watson, J. G., Ambs, J. L., Meyer, M. B., Hopke, P. K., Al-Horr, R., Later, D. W., and Wilson, W. E.: Measurement of both nonvolatile and semi-volatile fractions of fine particulate matter in Fresno, CA, Aerosol Sci. Technol., 40, 811-826, 2006.

Guazzotti, S. A., Coffee, K. R., and Prather, K. A.: Continuous measurements of size-resolved particle chemistry during INDOEXIntensive Field Phase 99, J. Geophys. Res. Atmos, 106(D22), 28607-28627, doi:10.1029/2001JD900099, 2001.

Hand, J. L. and Kreidenweis, S. M.: A new method for retrieving particle refractive index and effective density from aerosol size distribution data, Aerosol Sci. Technol., 36, 1012-1026, 2002.

Healy, R. M., Hellebust, S., Kourtchev, I., Allanic, A., O'Connor, I. P., Bell, J. M., Healy, D. A., Sodeau, J. R., and Wenger, J. C.: Source apportionment of $\mathrm{PM}_{2.5}$ in Cork Harbour, Ireland using a combination of single particle mass spectrometry and quantitative semi-continuous measurements, Atmos. Chem. Phys., 10, 9593-9613, doi:10.5194/acp-10-9593-2010, 2010.

Hinds, W. C.: Aerosol Technology: Properties, Behaviour, and Measurement of Airborne Particles, John Wiley, New York, 1982.

Hinz, K. P., Trimborn, A., Weingartner, E., Henning, S., Baltensperger, U., and Spengler, B.: Aerosol single particle composition at the Jungfraujoch, J. Aerosol Sci., 36, 123-145, 2005.

Janssen, N. A. H., Brunekreef, B., van Vliet, P., Aarts, F., Meliefste, K., Harssema, H., and Fischer, P.: The relationship between air pollution from heavy traffic and allergic sensitization, bronchial hyperresponsiveness, and respiratory symptoms in Dutch schoolchildren, Environ. Health Perspect., 111, 1512 1518, 2003.

Jayne, J. T., Leard, D. C., Zhang, X. F., Davidovits, P., Smith, K. A., Kolb, C. E., and Worsnop, D. R.: Development of an aerosol mass spectrometer for size and composition analysis of submicron particles, Aerosol Sci. Technol., 33, 49-70, 2000.

Jeong, C.-H., Hopke, P. K., Kim E., and Lee, D.-W.: The comparison between thermal-optical transmittance elemental carbon and Aethalometer black carbon measured at multiple monitoring sites, Atmos. Environ., 38, 5193-5204, 2004.

Jeong, C.-H. and Evans, G. J.: Inter-comparison of a fast mobility particle sizer and a scanning mobility particle sizer incorporating an ultrafine water-based condensation particle counter, Aerosol Sci. Technol., 43, 364-373, 2009.

Jeong, C.-H., Evans, G. J., McGuire, M. L., Chang, R. Y.-W., Abbatt, J. P. D., Zeromskiene, K., Mozurkewich, M., Li, S.-M., and Leaitch, W. R.: Particle formation and growth at five rural and urban sites, Atmos. Chem. Phys., 10, 7979-7995, doi:10.5194/acp10-7979-2010, 2010.

Jeong, C.-H., McGuire, M. L., Herod, D., Dann, T., DabekZlotorzynska, E., Wang, D., Ding, L., Celo, V., Mathieu, D., and Evans, G. J.: Receptor modeling based identification of the sources of $\mathrm{PM}_{2.5}$ in Canadian cities, Atmos. Pollution Res., 2, 
158-171, 2011.

Jimenez, J. -L., Jayne, J. T., Shi, Q., Kolb, C. E., Worsnop, D. R., Yourshaw, I., Seinfeld, J. H., Flagan, R. C., Zhang, X. F., Smith, K. A., Morris, J. W., and Davidovits, P.: Ambient aerosol sampling using the Aerodyne Aerosol Mass Spectrometer, J. Geophys. Res., 108(D7), 8425, doi:10.1029/2001JD001213, 2003.

Kamphus, M., Ettner-Mahl, M., Klimach, T., Drewnick, F., Keller, L., Cziczo, D. J., Mertes, S., Borrmann, S., and Curtius, J.: Chemical composition of ambient aerosol, ice residues and cloud droplet residues in mixed-phase clouds: single particle analysis during the Cloud and Aerosol Characterization Experiment (CLACE 6), Atmos. Chem. Phys., 10, 8077-8095, doi:10.5194/acp-10-8077-2010, 2010

Kane, D. B. and Johnston, M. V.: Size and composition biases on the detection of individual ultrafine particles by aerosol mass spectrometry, Environ. Sci. Technol., 34, 4887-4893, 2000.

Khlystov, A., Stanier, C., and Pandis, S. N.: An algorithm for combining electrical mobility and aerodynamic size distributions data when measuring ambient aerosol, Aerosol Sci. Technol., 38(S1), 229-238, 2004.

Künzli, N., Mudway, I. S., Go“tschi, T., Shi, T., Kelly, F. J., Cook, S., Burney, P., Forsberg, B., Gauderman, J. W., Hazenkamp, M. E., Heinrich, J., Jarvis, D., Norba“ck, D., Payo-Losa, F., Poli, A., Sunyer, J., and Borm, P. J. A.: Comparison of oxidative properties, light absorbance, and total and elemental mass concentration of ambient $\mathrm{PM}_{2.5}$ collected at 20 European sites, Environ. Health Perspect., 114, 684-690, 2006.

Liu, D. Y., Rutherford, D., Kinsey, M., and Prather, K. A.: Realtime monitoring of pyrotechnically derived aerosol particles in the troposphere, Anal. Chem., 69, 1808-1814, 1997.

Long, R. W. and McClenny, W. A.: Laboratory and field evaluation of instrumentation for the semicontinuous determination of particulate nitrate (and other water-soluble particulate components), J. Air Waste Manage. Assoc., 56, 294-305, 2006.

Middlebrook, A. M., Murphy, D. M., Lee, S. H., Thomson, D. S., Prather, K. A., Wenzel, R. J., Liu, D. Y., Phares, D. J., Rhoads, K. P., Wexler, A. S., Johnston, M. V., Jimenez, J. L., Jayne, J. T., Worsnop, D. R., Yourshaw, I., Seinfeld, J. H., and Flagan, R. C.: A comparison of particle mass spectrometers during the 1999 Atlanta Supersite Project, J. Geophys. Res. Atmos., 108(D7), 8424, doi:10.1029/2001JD000660, 2003.

McGuire, M. L., Jeong, C.-H., Slowik, J. G., Chang, R. Y.-W., Corbin, J. C., Lu, G., Mihele, C., Rehbein, P. J. G., Sills, D. M. L., Abbatt, J. P. D., Brook, J. R., and Evans, G. J.: Elucidating determinants of aerosol composition through particletype-based receptor modeling, Atmos. Chem. Phys. Discuss., 11, 9831-9885, doi:10.5194/acpd-11-9831-2011, 2011.

Moffet, R. C., de Foy, B., Molina, L. T., Molina, M. J., and Prather, K. A.: Measurement of ambient aerosols in northern Mexico City by single particle mass spectrometry, Atmos. Chem. Phys., 8, 4499-4516, doi:10.5194/acp-8-4499-2008, 2008.

Moreno, T., Querol, X., Alastuey, A., Minguillón, M. C., Pey, J., Rodriguez, S., Miró, J. V., Felis, C., and Gibbons, W.: Recreational atmospheric pollution episodes: inhalable metalliferous particles from fireworks displays, Atmos. Environ., 41, 913-922, 2007.

Myhre, G., Grini, A., and Metzger, S.: Modelling of nitrate and ammonium-containing aerosols in presence of sea salt, Atmos. Chem. Phys., 6, 4809-4821, doi:10.5194/acp-6-4809-2006,
2006.

Peters, T. M. and Leith, D.: Concentration measurement and counting efficiency of the aerodynamic particle sizer 3321, J. Aerosol Sci., 34, 627-634, 2003.

Phares, D. J., Rhoads, K. P. Wexler, A. S. Kane, D. B. and Johnston, M. V.: Application of the ART-2a algorithm to laser ablation aerosol mass spectrometry of particle standards, Anal. Chem., 73, 2338-2344, 2001.

Pitz, M., Schmid, O., Heinrich, J., Birmili, W., Maguhn, J., Zimmermann, R., Wichmann, H. E., Peters, A., and Cyrys, J.: Seasonal and diurnal variation of PM2.5 apparent particle density in urban air in Augsburg, Germany, Environ. Sci. Technol., 42, 5087-5093, 2008.

Pourazar, J., Mudway, I. S., Samet, J. M., Helleday, R., Blomberg, A., Wilson, S. J., Frew, A. J., Kelly, F. J., and Sandström, T.: Diesel exhaust activates redox-sensitive transcription factors and kinases in human airways, Am. J. Physiol. Lung Cell. Mol. Physiol., 289, L724-L730, 2005.

Pratt, K. A. and Prather, K. A.: Real-time, single-particle volatility, size, and chemical composition measurements of aged urban aerosols, Environ. Sci. Technol., 43, 8276-8282, 2009.

Qin, X., Bhave, P. V., and Prather, K. A.: Comparison of two methods for obtaining quantitative mass concentrations from aerosol time-of-flight mass spectrometry measurements, Anal. Chem., 78, 6169-6178, 2006.

Quinn, P. K., Bates, T. S., Coffman, D., Onasch, T. B., Worsnop, D., Baynard, T., de Gouw, J. A., Goldan, P. D., Kuster, W. C., Williams, E., Roberts, J. M., Lerner, B., Stohl, A., Pettersson, A., and Lovejoy, E. R.: Impacts of sources and aging on submicrometer aerosol properties in the marine boundary layer across the gulf of Maine, J. Geophys. Res. Atmos., 111, D23S36, doi:10.1029/2006JD007582, 2006.

Rehbein, P. J. G., Jeong, C. -H., McGuire, M. L., Yao, X., Corbin, J. C., and Evans, G. J.: Cloud and fog processing enhanced gas-toparticle partitioning of trimethylamine, Environ. Sci. Technol., 45, 4346-4352, 2011.

Reilly, P. T. A., Lazar, A. C., Gieray, R. A., Whitten, W. B., and Ramsey, J. M.: The elucidation of charge-transfer-induced matrix effects in environmental aerosols via real-time aerosol mass spectral analysis of individual airborne particles, Aerosol Sci. Technol., 33, 135-152, 2000.

Reinard, M. S. and Johnston, M. V.: Ion formation mechanism in laser desorption ionization of individual nanoparticles, J. Am. Soc. Mass Spectrom., 19, 389-399, 2008.

Reinard, M. S., Adou, K., Martini, J. M., and Johnston, M. V.: Source characterization and identification by real-time single particle mass spectrometry, Atmos. Environ., 41, 9397-9409, 2007.

Schwab, J. J., Spicer, J., Demerjian, K. L., Ambs, J. L., and Felton, H. D.: Long-term field characterization of TEOM and modified TEOM samplers in urban and rural New York State locations, J Air Waste Manage. Assoc., 54, 1264-1280, 2004.

Schwab J. J., Felton, H. D., Rattigan, O. V., and Demergian, K. L.: New York State urban and rural measurements of continuous $\mathrm{PM}_{2.5}$ mass by FDMS, TEOM, and BAM, J. Air Waste Manage. Assoc., 56, 372-383, 2006.

Schwartz, J., Dockery, D. W., and Neas, L. M.: Is daily mortality associated specifically with fine particles?, J. Air Waste Manage. Assoc., 46, 2-14, 1996. 
Sioutas, C., Abt, E., Wolfson, J. M., and Koutrakis, P.: Evaluation of the measurement performance of the Scanning Mobility Particle Sizer and Aerodynamic Particle Sizer, Aerosol Sci. Technol., 30, 84-92, 1999.

Song, X. H., Hopke. P. K., Fergenson, D. P., and Prather, K. A.: Classification of single particles analyzed by ATOFMS using an artificial neural network, ART-2a, Anal. Chem., 71, 860-865, 1999.

Spencer, M. T. and Prather, K. A.: Using ATOFMS to determine OC/EC mass fractions in particles, Aerosol Sci. Technol., 40, 585-594, 2006.

Squadrito, G. L., Cueto, R., Dellinger, B., and Pryor, W. A.: Quinoid redox cycling as a mechanism for sustained free radical generation by inhaled airborne particulate matter, Free Radic. Biol. Med., 31, 1132-1138, 2001.

Stohs, S. J. and Bagchi, D.: Oxidative mechanisms in the toxicity of metal ions, Free Radic. Biol. Med., 18, 321-336, 1995.

Sullivan, R. C., Guazzotti, S. A., Sodeman, D. A., and Prather, K. A.: Direct observations of the atmospheric processing of Asian mineral dust, Atmos. Chem. Phys., 7, 1213-1236, doi:10.5194/acp-7-1213-2007, 2007.

Thorne, P. S.: Inhalation toxicology models of endo-toxin- and bioaerosol-induced inflammation, Toxicology, 152, 13-23, 2000.
Tolocka, M. P., Reinard, M. S., Lake, D. A., Ondov, J. M., Wexler, A. S., and Johnston, M. V.: Characterization of short-term particulate matter events by real-time single particle mass spectrometry, Aerosol Sci. Technol., 40, 873-882, 2006.

Turpin, B. J. and Lim, H. -J.: Species contributions to $\mathrm{PM}_{2.5}$ mass concentrations: Revisiting common assumptions for estimating organic mass, Aerosol Sci. Technol., 35, 602-610, 2001.

Wenzel, R. J. and Prather, K. A.: Improvements in ion signal reproducibility obtained using a homogeneous laser beam for on-line laser desorption/ionization of single particles, Rapid Commun. Mass Spectrom., 18, 1525-1533, 2004.

Wenzel, R. J., Liu, D. -Y., Edgerton, E. S., and Prather, K. A.: Aerosol time-of-flight mass spectrometry during the Atlanta $\mathrm{Su}-$ persite Experiment: 2. Scaling procedures, J. Geophy. Res., 108(D7), 8427, doi:10.1029/2001JD001562, 2003.

Zhang, Y., Wanga, X., Chen, H., Yang, X.., Chen, J., and Allen, J. O.: Source apportionment of lead-containing aerosol particles in Shanghai using single particle mass spectrometry, Chemosphere, 74, 501-507, 2009.

Ziemba, L. D., Fischer, E. Griffin, R. J., and Talbot, R. W.: Aerosol acidity in rural New England: Temporal trends and source region analysis, J. Geophys. Res., 112, D10S22, doi:10.1029/2006JD007605, 2007. 